\title{
ADAPTING TO BORN-DIGITAL PHOTOGRAPHS: A CASE STUDY OF THE CANADIAN CENTRE FOR ARCHITECTURE
}

\author{
by \\ Saba Moghtader \\ BFA OCAD University, Toronto, Ontario, 2015
}

\author{
A Master Research Paper \\ presented to Ryerson University \\ in partial fulfillments of the requirements for the degree of \\ Master of Arts \\ in the program of
}

Film and Photography Preservation and Collections Management

Toronto, Ontario, Canada, 2019

(C) Saba Moghtader, 2019 


\section{AUTHOR'S DECLARATION FOR ELECTRONIC SUBMISSION OF A MRP}

I hereby declare that I am the sole author of this MRP. This is a true copy of the MRP, including any required final revisions, as accepted by my examiners.

I authorize Ryerson University to lend this MRP to other institutions or individuals for the purpose of scholarly research.

I further authorize Ryerson University to reproduce this MRP by photocopying or by other means, in total or in part, at the request of other institutions or individuals for the purpose of scholarly research.

I understand that my MRP may be made electronically available to the public. 
Adapting to Born-Digital Photographs: A Case Study of The Canadian Centre for Architecture Master of Arts, 2019

Saba Moghtader

Film and Photography Preservation and Collections Management

Ryerson University

\section{Abstract}

As born-digital photography collections grow, so grows the need for a more defined set of guidelines on the best practices of how to acquire, describe and preserve said photographs. This paper is the result of a practical project conducted at the Canadian Centre for Architecture. The project uses the CCA as a case study and asks the question: how is the Centre adapting to the collection of born-digital photographs? During a six-month residency, the author, developed and implemented a description guideline, workflow, and donor guideline for the collection and cataloguing of born-digital photographs. These guidelines are the result of the steady growth in the volume of born-digital photographs coupled with the need for ensuring long term preservation for existing and potential collections.

The aim of this paper is to help improve the usefulness and clarity of the guidelines. The case study and paper was conducted in conjunction with the requirements of Film and Photography Preservation and Collections Management (FPPCM) master's at Ryerson University. The title of the guideline is Guidelines for Describing Born-Digital Photograph. 


\section{Acknowledgments}

First, I would like to express my fervent gratitude to Dee Psaila for her patience, encouragement support and invaluable guidance throughout my MRP. Besides my advisor, I would like to thank Robert Burley my second reader and the students and faculty of the FPPCM program.

My sincerest thanks and acknowledgement also goes to Louis Désy, Curator of Photographs at the CCA, for her generosity in opening the collection to me, and for her endless guidance and motivation. I would also like to thank Martien de Vletter, the Director of Collections at the CCA, Stefana Breitwieser, Alexandra Jokinen and the entire Digital department at the CCA for their openness to share their work and knowledge with me.

I also want to extend the deepest recognition to Stefana Breitwieser, Alan Reed, David Stevenson, Alexandra Jokinen, Tim Walsh, Emily Sommers, Amy Furness and Robert Burley for participating in the interviews for this MRP.

Lastly, I would like to thank my friends and family for the emotional and intellectual support they afforded me, without whom this process would have never seen completion. 


\section{Table of Contents}

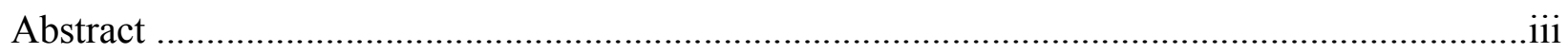

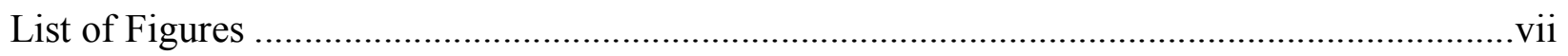

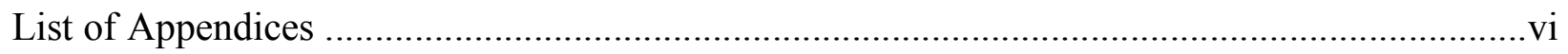

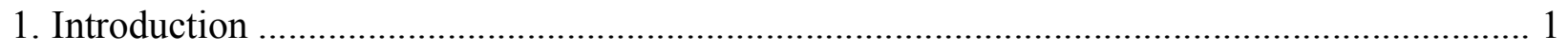

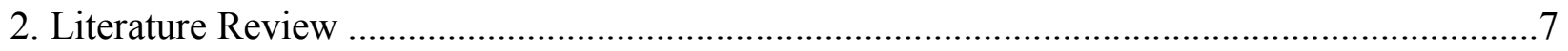

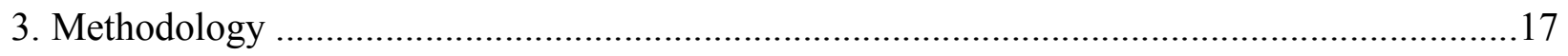

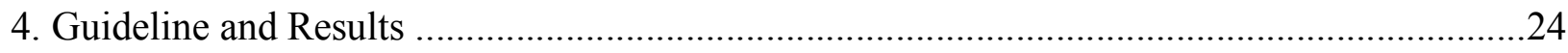

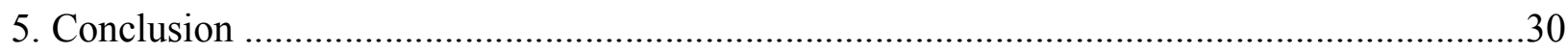

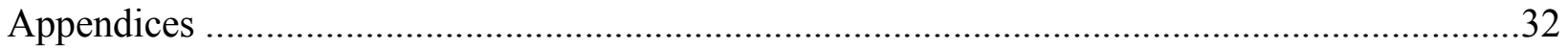

Appendix A - CCA Guidelines for Describing Born-Digital Photographs ...................................32

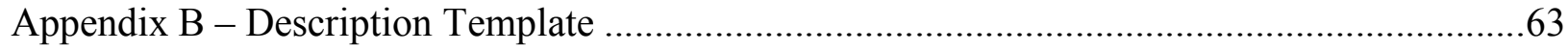

Appendix C - Documentation Related to Interviews …………………...................................68

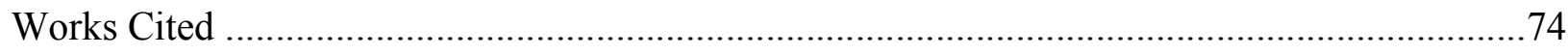

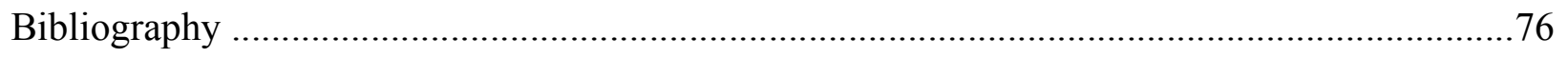




\section{List of Figures}

Figure 1. Definitions of the 4 Categories of Metadata, taken from article from Information Standards Quarterly Titled Digital Preservation Metadata Standards, page 16

Figure 2 - Flowchart of key steps for the donation and receival of born-digital materials, taken from Born Digital: Guidance for Donors, Dealers, and Archival Repositories, $\quad$ page 13

Figure 3 - Example of Born-Digital field in the CCA Guidelines for Describing Born-Digital Photographs, Page 7

Figure 4 - Example of Born-Digital field in the CCA Guidelines for Describing Born-Digital Photographs, Page 5 


\section{List of Appendices}

Appendix A - CCA Guidelines for Describing Born-Digital Photographs, page 32 Appendix B - Description Template,

page 63

Appendix C - Documentation Related to Interviews,

page 68 


\section{Introduction}

Digital photography requires an unprecedented level of engagement by the archivist throughout the entire lifecycle of the records, but given the size of the problem where does the archivist begin?

BRIAN KEOUGH and MARK WOLFE

Today, there is an undeniable prevalence in the creation and circulation of photographs that are created and viewed digitally, which from here on out will be referred to as born-digital photographs. With the growth of social media platforms and new artistic practices it appears that the creation of this type of image will not be slowing down but will continue to grow substantially. Almost everyone carries a digital camera and is constantly taking photographs. Back in 2015 it was estimated that more than 1.3 trillion digital photos will be taken in 2017. (Heyman 2015) It has been hard to verify this, however the number itself is astonishing. With the closing down of analogue facilities and the discontinuation of many analogue formats, most photographers have shifted their practice to the digital. They are also beginning to think about donating their digital files to institutions to insure the safeguarding of this new type of photograph. With this ubiquity comes concerns of preservation and ensuring that this material, whether personal images or works of art, endures the test of time.

There are numerous known and unknown issues surrounding born digital photographs, which in many ways differ from analogue photographs. For example, Sarah Sevenson cites "Vint Cerf, chief evangelist at Google, warn[ing] of a potential digital dark age, a future where it will be difficult to read historical electronic media because they were left in obsolete or obscure file formats" (Severson 2017, 2) She furthermore, suggests that the volume of digital images coupled with the risks of software and hardware failure, hardware obsolescence, bit rot and the risk of 
metadata loss through migration are a few of the issues that are a real concern when thinking of the preservation of born-digital photographs. (Severson 2017, 2)

It is important to establish what born-digital objects are in order to begin thinking about their preservation. A born-digital object can be defined as an item that has no analogue form. Or rather it is an object that did not originate from an analogue or physical 'hard copy'. (Erway 2010, 1) Kenneth Thibodeau in his definition of born-digital presents the complexity and diversity of born-digital objects and posits that "the variety and complexity of digital information objects engender a basic criterion for evaluating possible digital preservation methods, namely, they must address this variety and complexity." (Thibodeau 2018) So, how can collecting institutions, of varying sizes, tackle the preservation of born-digital objects and how will the strategies in place differ when applied to born-digital photographs?

Note on terminology - From here on out there is a distinction between born-digital objects/materials and born-digital photographs, in that born-digital photographs are a type of borndigital material but the opposite is not always true.

\subsection{Background}

Born-digital materials and specifically photographs are not a new phenomenon, however, their inclusion in collections is still relatively new. The first examples of digital objects in collections were not acquisitioned material, rather digital technologies aided in creating facsimiles as preservation techniques. This history is similar to the history of photography itself in collections, where photography was used to document and catalogue what was in the collection. Propelling this forward were the technological changes in how images were created and ultimately how they 
are viewed now. Online databases required Galleries, Libraries, Archives and Museums (GLAM) institutions to adapt and digitize their collections to be made available online. This resulted in institutions now having large digital photography collections to manage.

A lot of progression has occurred in recognizing the historical importance of these materials throughout the past 20-30 years with more born-digital objects being accessioned into collections, despite these institutions being still hesitant to acquire born-digital photographs. My research suggests that many institutions are either having difficulty adapting to digital collections, or are outright refusing to collect such materials because of a lack of resources. Based on the history of digital collections there is more literature addressing the issues surrounding born-digital collections materials in archives and libraries but there has been little said on the quandaries specific to born-digital photographs in museum collections.

How can cultural heritage institutions ensure the safe guarding of such content without adequate procedures in place? There are numerous guidelines and standards that solely focus on born-digital materials, however, photography often takes up a small section if at all mentioned. This is alarming as more photographers are shifting their practice from analogue to digital processes. As Brian Keough and Mark Wolfe suggest in their 2012 article "there remain too few examples documented by repositories that demonstrate practical methods and tools for providing access and preservation for born-digital images, and such practical approaches deserve more attention." (Keough and Wolfe 2012, 70) There are many factors, such as structural organization within institutions, lack of funds and resources, and priorities that play into the lack of documentation. For example, in larger institutions, there is often no department dedicated to digital 
collections. This results in work from across a number of departments where there is little space for accountability and the lack of impetus to take on the development of such documentations.

\subsection{Introduction to the Collection}

We're not a museum that puts things out and says, 'this is architecture.' We try to make people think.

Phyllis Lambert

The Canadian Centre for Architecture (CCA), located in Montreal, Canada is a 12,000 square meter exhibition space, library and archive. This institution was founded in 1979 by architect and philanthropist Phyllis Lambert. Throughout her career she has been dedicated to the preservation of heritage buildings in Montreal. In 1975, Lambert founded the group Heritage Montreal, whose main goal is to raise money to help with the conservation of heritage sites around Montreal, the group has also been instrumental in stopping numerous demolitions. This obligation towards preservation was the root of her move to establish the CCA. "While promoting conservation and renovation, Lambert, who had amassed a vast collection of architectural photographs, books and other documents, decided an institution was needed to foster awareness and stimulate research in the field [of architecture].” (Marian 2017, n.d.) In 1974, Lambert bought the Shaughnessy house, which was in danger of being destroyed, and with local architect Peter Rose renovated this historic residence to work with a newly created adjoining building that is now known as the CCA. The Centre's current mandate is "to collect, as a museum and research library; to archive and document; to support research, as a study centre; and to create and disseminate knowledge through exhibitions, publications, and public programs." (CCA about, n.d.)

The CCA has a vast collection which includes books, prints and drawings, architectural artifacts and ephemera, architect archives, and a photography collection spanning the entire history 
of the medium. They also have a strong philosophy presented on their online database. "The CCA recognizes the need for two buildings: the physical one anchored to its specific place in Montreal, and the digital one to be accessed online from any place at any time." (CCA, n.d.) As a result of this, the CCA is the ideal space for a case study that looks how an institution is adapting to collecting born-digital photographs. First, the CCA has nearly 200 full or project archives of contemporary architects and artists. Due to the nature of their collections and the mandates of their institution, the CCA has needed to adjust to born-digital objects entering their collections. The $\mathrm{CCA}$, for a number of years has been collecting from contemporary architects, which as a result of how architects work, led to collecting born-digital materials. Second, and significantly to this project, since it is looking at adopting existing practices, is how the CCA has tackled this shift in collections materials. This has been done through a project called Archeology of the Digital which took place between $2013-2016$ and allowed the CCA to reflect on and acquire born-digital materials and tools used in architecture. This project has also led to the development of the digital department which has been instrumental in laying the foundation for allowing the photography department to begin to collect born-digital photographs. This is important to note because the architecture archives and photography department at the CCA are separated. It is then no surprise that a collaborative space can form, where the reflections taken on born-digital objects can now be applied to photography. And lastly, based on the long history of photography and architecture, the CCA has a large collection of photographs from architecture firms and photographers who focus on architecture. As a conceptually driven institution, the Centre also collects and commissions many works from photographers resulting in a diverse collection. This mandate allows them to have works that are different from the 'traditional photography as documentation' philosophy that is prevalent in architecture photography. This is important to note since much of the literature 
about born-digital objects in collections are from the viewpoint of archives and libraries and not as works of art in museum collections. Working with contemporary artists coupled with the CCA's desire to collect born-digital materials as a whole has allowed them to have a number of borndigital photographs already in the collection. This served as my case study for the development of a set of guidelines that are specific to born-digital photographs. The title of the guideline is Guidelines for Describing Born-Digital Photographs, and from here on out will be referred to as (this, the) guideline.

The impetus for providing guidance to collections managers at all types of institutions, specifically, and taking up the challenges of born-digital photography preservation, generally, is multi-dimensional. Aside from the need for a guideline at the CCA, this project is the result of the new advances in digital technologies which have led to a steady growth in the volume of borndigital photographs coupled with the need for ensuring long term preservation for existing and potential collections. The project uses the CCA as a case study and asks the question: how is the CCA adapting to collecting born-digital photographs?

The aim was to create a guideline which uses as its' point of departure, the collecting of borndigital photographs, the workflows in place, and the considerations in description and metadata to manage born-digital photography collections. More specifically, the objective of this guideline is to assist photography cataloguers and collections managers at the different stages of born-digital photography processing in order to ensure continuity and parity between the description of their analogue and of their born-digital photography holdings in their database. The aim of this guideline and paper is also to provide other institutions, of a variety of sizes, the tools to develop and adapt their own best practices. 


\section{Literature Review}

Prior to starting to delve into working within the collection at the CCA for my case study, it was important to examine the current writings and approaches to this modern collecting conundrum. There is a fair amount of material on the subject, as clearly this sudden shift in collection practices and new objects that require technological infrastructure, training and acceptance into the world of perpetuity are thought provoking to many. I have organized my findings into five sections: born-digital photography in collection management, reflections on archival and museum description standards, metadata standards, the creation of procedures, and lastly, the role of donors in the collection of born-digital materials.

\subsection{Born-Digital Collections Management and Preservation}

Kenneth Thibodeau, in his 2018 conference paper Overview of Technological Approaches to Digital Preservation and Challenges in Coming Years posed some crucial questions associated with the preservation of digital objects. Questions such as "What does it mean to preserve digital objects? What purposes are served by preserving them? What are the real possibilities for successful preservation? What are the problems encountered in trying to exploit these possibilities? And can we articulate a framework or an overall architecture for digital preservation?" (Thibodeau $2018,1)$ These questions are integral to the foundation of my research moving forward. The main point Thiboudeau presents is a paradox that is inherent to digital preservation. He says that "on the one hand [the aim of digital preservation is] to deliver the past to the future in an unaltered, authentic state [which is the case with most preservation strategies]. On the other hand, doing so inevitably requires some alteration." (Thibodeau 2018, 27) His suggestion is that a digital preservation strategy needs to be evolutionary in order to be successful. "If the preservation 
solution cannot grow and adapt to continuing changes in the nature of the problem and continuing escalation of user demands, the 'solution' itself will in short order become part of the problem; that is, it will itself become obsolete." (Thibodeau 2018, 27)

A short coming of this text is that although there is some refence to preservation of digital photography as it differs from analogue, the focus is on photographs in archives as opposed to digital art photography which is at the centre of this case study.

\subsection{Archival \& Museum Description}

A group of four librarians and archivists, Annalise Berdini, Charles Macquarie, Shira Peltzman, and Kate Taskerfrom from the University of California (UC) system set out to create a standard for the description of born-digital objects in their library. It is called the UC Guidelines for Born-Digital Archival Description. The guideline, which is available online has been integral in the development of the guidelines created in this case study. In an article called Describing Digital: The Design and Creation of a Born-Digital Archival Description Standard at the University of California Libraries, these four professionals present the detailed process of the factors that aided in the realization of the standard. An impetus to create these guidelines stemmed from the fact that no other description standard considered these elements in this way. Despite being an invaluable resource for the guidelines of this paper, the UC Guidelines are inadequately general in describing born-digital material as a whole and provide little to no specific suggestions for born-digital photographs.

The descriptive elements that will be found in the CCA guidelines that have been adapted from the UC guidelines are Source of Acquisition, Physical Description, Technical Requirements 
and Processor. Most of the elements used in the CCA guideline can be found in other standards, however few clearly outline how they can be adapted to born-digital photographs specifically, which would ensure consistency and clarity.

\subsection{Metadata Standards}

Metadata is data that can be linked or embedded in a digital object to help aid with classification, access and provenance. (Rubinstein and Sluis 2013, 151) To better organize and understand metadata it is often separated into subcategories which include biographic or descriptive, structural, technical and administrative metadata.

\footnotetext{
1 Descriptive metadata

Describes the intellectual entity through properties such as author and title, and supports discovery and delivery of digital content. It may also provide an historic context, by, for example, specifying which print-based material was the original source for a digital derivative (source provenance).

2 Structural metadata

Captures physical structural relationships, such as which image is embedded within which website, as well as logical structural relationships, such as which page follows which in a digitized book.

3 Technical metadata for physical files

Includes technical information that applies to any file type, such as information about the software and hardware on which the digital object can be rendered or executed, or checksums and digital signatures to ensure fixity and authenticity. It also includes content type-specific technical information, such as image width for an image or elapsed time for an audio file.

4. Administrative metadata

Includes provenance information of who has cared for the digital object and what preservation actions have been performed on it, as well as rights and permission information that specifies, for example, access to the digital object, including which preservation actions are permissible.
}

Figure 1. Definitions of the 4 Categories of Metadata, taken from article from Information Standards Quarterly titled "Digital preservation Metadata Standards", page 16. 
Both Digital Preservation Metadata Standards by Angela Dappert and Marcus Enders and Linking Collection Management Policy to Metadata for Preservation - A Guidance Model to Define Metadata Description Levels In Digital Archives by Maria Luisa Calanag, Koichi Tabata and Shigeo Sugimoto provide a technical look at the elements and basic standards of how metadata can be used and understood in archives. They provide resources such PREMIS (PREservationMetadata: Implementation Strategies) which is a data dictionary for metadata preservation created by the Library of Congress to aid in the preservation of digital objects, (PREMIS website) and provide explanations for elements such as METS (Metadata Encoding and Transmission Standard), AIP's (Archival Information Package), SIP's (Submission Information Package), and DIP's (Dissemination Information Package).

Dappert and Enders make a case for why metadata is needed and define what each subcategories of metadata are. They also make the claim that "while communities have a strong desire for long-lasting, stable metadata standards, they continue to evolve as the number of repository implementations and applications grows. Experience remains too limited to set a preservation metadata standard in stone." (Dappert and Enders 2010,11)

Maria Luisa Calanag, Koichi Tabata, Shigeo Sugimoto, emphasize that the benchmark for preservation is that "the preserved digital object can be found, and that the preserved digital object be understood." (Calanag, Tabata and Sugimoto 2002, 42) As a result of this, the argument of this paper is a set of guidelines for policy development that encompasses long-term preservation and metadata for born-digital materials in academic environments. They highlight that preservation needs to be an integral part of a collections policy, which includes donor submission policies. The authors also present a framework for collections managers to turn to when defining their own 
appropriate metadata based on their specific needs. For example, the authors reference The Cedars Project which "coined the term 'significant properties' to describe those components of a digital object deemed necessary for its long-term preservation." (Calanag, Tabata and Sugimoto 2002, 37) They suggest that specifying these properties will dictate the level of metadata that must accompany the digital object. (Calanag, Tabata and Sugimoto 2002, 37). Lastly, and perhaps most importantly, the authors set forth the notion that determining the "granularity of the preservation metadata ... will insure that the digital materials will be preserved and accessed over time" (Calanag, Tabata and Sugimoto 2002, 39) The suggested method of doing this is to identify the degrees of persistence in the digital object as high confidence for preservation and access, medium confidence for preservation and access, or low confidence for preservation and access.

Although this article is specifically looking to give a guide for adapting and creating collections policies, which is not directly linked to the work of this study, there are many useful suggestions about how integrate preservation and metadata into a workflow. This is one of the main areas of this case study, the development of creating a workflow for born-digital photographs at the CCA.

There is a consensus that the definition of metadata as "data about data" is limiting. Daniel Rubinstein and Katrina Sluis in their article Notes on the Margins of Metadata: Concerning The Undecidability of the Digital Image further emphasize the notion that this description of metadata is "unhelpful because it does not clarify metadata's place as a mediator between humans and computers." (Rubinstein and Sluis 2013, 152) The authors describe metadata in relation to images on the web and go on to outline the importance of metadata in allowing better access to digital objects while also presenting the challenges with digital images. 
Gerg Bak in an article from 2006 titled Not Meta Just Data: Redefining Content and Metadata in Archival Theory and Practice calls for a change in how data is collected and used in archival settings.

Metadata is an important area when thinking about the best way to preserve born-digital objects. It also an area of confusion and nuance. Unlike non-digital materials, when it comes to digital objects there is no clear separation between content and metadata. (Bak 2016, 4) Metadata is embedded in the digital file and with this arrives questions about how to manage and record it in cultural heritage collections. For example, a common issue to consider is how metadata is generated. Is it human or auto-generated? If human, how does one ensure consistency; if autogenerated, how does one let users know that this information is the result of an algorithm?

On a more conceptual level politics are inherent in metadata as it helps create context for otherwise orphaned images. Metadata also "specifies topologies between images; [and] its development and use promises to democratize access to disparate digitized image collections...” (Rubinstein and Sluis 2013,152) With this arises questions about authenticity. As Rubinstein and Sluis set forth,

In this climate [of networked images] repetition, seriality and divergent parallel narratives take precedence over signification and representation. This destabilisation of photographic meaning is the direct result of the image being detached from its teleological origins. Traditional ontologies of photography maintain an identity between the moment of exposure and all subsequent images, copies and prints that follow from it. (pg.154)

What the authors are suggesting here is that born-digital photographs question the hierarchy and historical modes of representation. 


\subsection{Policies and Procedures}

In an article titled Moving the Archivist Closer to the Creator: Implementing Integrated Archival Policies for Born Digital Photography at Colleges and Universities, Brian Keough and Mark Wolfe, use university and college archives for their examination of the shift from analogue photography to digital photography and the important relationship between archivist and photographer. They conclude that archivists need to play a more active role in how photographers organize and manage their digital content. The authors discuss the importance of policies required for acquisition, preservation, description and dissemination of born-digital photographs. This journal article is significant to this study because it looks specifically at how born-digital photographs are treated in institutions while highlighting the importance of evolving documentation.

The 2016 article titled Born-Digital Art: Documentation Models as a Conservation Measure by Amelia Boogen is one of the few articles found that specifically calls to attention the importance of revising and developing documentation to preserve born-digital art. She provides a useful definition of documentation as "the material that illustrates, shows, provides instruction, or supplies evidence of an activity in relation with a work of art" (Boogen-Ybarra 2016,166) Consistent modifications and altercations are a key preservation technique for born-digital materials. This notion is also highlighted by Kenneth Thibodeau. Here, Boogen-Ybarra advocates that documentation should be a central point in recording these changes and revisions. (BoogenYbarra 2016,166)

Ybarra furthermore, emphasises that what is pertinent in documentation is a representation of the "artist's intent and purpose (interviews); diagrams and technical details for the setting-up; 
... exact description ... and a description of the ideal spatial requirements for view." (BoogenYbarra 2016, 166) Although her focus is more on media art as whole, she presents numerous examples such as DOCAM (Documentation and Conservation of Media arts Heritage) which is an international research alliance developed in 2005 that provides "tools, guides and methods that contribute to the preservation of the media arts heritage." (DOCAM, nd)

Ultimately, both of these texts raise important concerns in managing the vastness of digital images and the role documentation has in ensuring preservation by way of policies, guidelines, and workflows.

\subsection{Donor's roles and practices}

The guide titled "Born Digital: Guidance for Donors, Dealers, and Archival Repositories" is the result of the collaboration of 10 archivists and special collections curators. They are Gabriela Redwine, Megan Barnard, Kate Donovan, Erika Farr, Michael Forstrom, William M Hansen, Jeremy Leighton John, Nancy Kuhl, Seth Shaw, and Susan Thomas. The text focuses on four areas to be noted during the process of born-digital acquisition to "ensure that digital materials are handled and documented appropriately and arrive at the repository in good condition" (Redwine and authors 2013, vi). The four areas are Initial Collections Review, Privacy and Intellectual Property, Key Stages in Acquiring Digital Materials, and Post-Acquisition Review by the Repository. Another critical aspect of this source is the appendices, which are extremely useful tools to help everyone involved. They range from a recommended list of tasks and the appropriate personnel for each task, to checklists and resources. One that stands out is appendix $\mathrm{C}-$ titled Preparing for the Unexpected which outlines some key issues to keep in mind, both from the perspective of the donor and the collecting institution. 
An issue that keeps coming up in each section of this guide is the necessity to collaborate. It is important that at every stage of the process, the donating party and the collecting institution work together to ensure the safe transfer of the material and that the necessary information is included. The flow chart below shows the basic requirements to insure best practice.

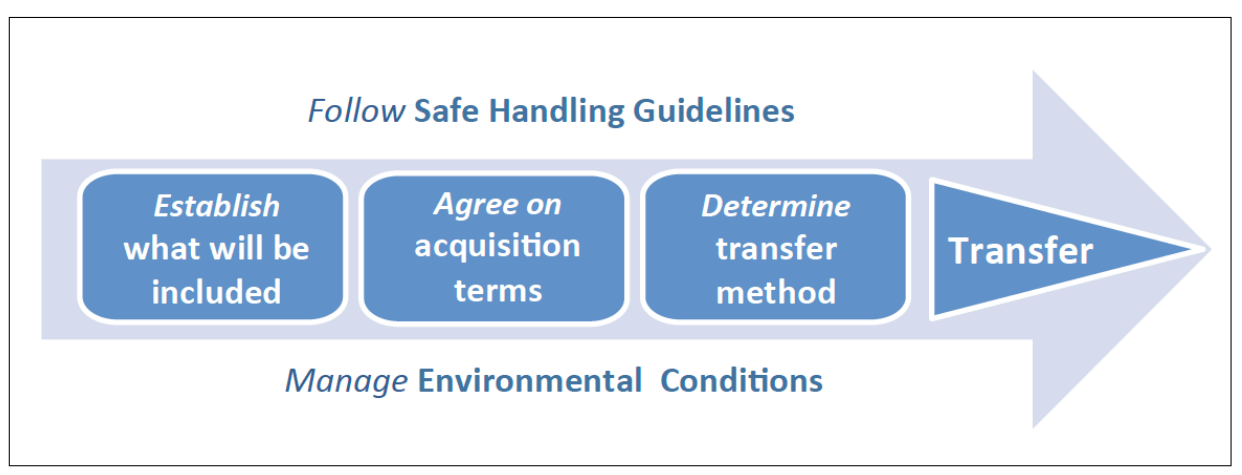

Figure 2 - Flowchart of key steps for the donation and receival of born-digital materials, taken from "Born Digital: Guidance for Donors, Dealers, and Archival Repositories”, page 13.

Although this text is extremely valuable in beginning to think about the donation process and the steps a repository needs to take in creating a seamless process, it is not specific to the considerations needed for born-digital photographs. Despite this, it is an excellent starting point in thinking about the very critical issues associated with donating and acquiring born-digital material.

\subsection{Conclusion}

It appears from the literature that GLAM institutions at times, for a litany of reasons, feel unequipped in collecting and preserving such materials. The literature further suggest that libraries and archives have had to adapt faster in thinking about born digital objects in their collections. I was able to find a number of guidelines and standards that focus solely on born digital materials 
but what became clear was that photography often took up only a small section or was not represented in these documents.

This literature review has both answered and shed light on some major issues surrounding born-digital preservation. Most notably, thinking about the best ways to describe born-digital photographs, with an emphasis on the role of metadata, to ensure accessibility and consistency and the collaborative nature of navigating the collection and preservation of born-digital photographs. Moreover, it has also revealed areas of quandary and uncertainty specifically as they relate to issues of authenticity in born-digital photography and the responsibility and development of workflows. 


\section{Methodology}

The CCA at the time of my arrival had two born-digital photography holdings and was looking to add more. Moreover, they wanted to add documentation and streamline the process of borndigital photography acquisitions. At first, I also thought there might be an opportunity to look at the technical aspects of the hardware and software required to begin collecting born-digital photography. However, as I began to dive into the photography collection I quickly noticed that the foundation had already been laid by the digital department and that there was a stronger need for a standardized approach to the description of born-digital photographs. This was the result of my time spent cataloguing my early days at the CCA.

The CCA uses The Museum System (TMS) as their main database. It has yet to be configured to consider born-digital specific fields. One aspect of the work that was expected of me was to make suggestions on how to adapt the existing fields to allow for uniformity and consistency and to ensure preservation and searchability as they collect more born-digital photographs. This is an important motivation for a description guideline since the CCA as an institution functions in a few ways, it is an archive and a museum; it is also a research centre and as part of its mandate as a research centre they consider their website as a "'second building,' where visitors can encounter the CCA's thinking, activities, and collection from wherever they are in the world." As a result of this philosophy, how the objects in their collection are cataloged is extremely important.

Since the archive department processes a larger quantity of materials and works closely with the digital department, the documentation for how to describe and catalogue born-digital material was better developed. Furthermore, since the archives holds a much larger quantity and variety of materials the documentation reflected the entirety of born-digital materials. The 
documentation was extremely general in how born-digital objects need to be catalogued. This resulted in the need for more specific instructions for born-digital photography.

A course of action had to be developed in order to strategize how to proceed with the task at hand. First, I needed to become familiar with the collection and review the existing documentation for photography and the digital archives. Existing documentation included a digital collections policy, workflows, description worksheets, and series of documents aimed to help digital archivists with data collection and input. Second, I needed to conduct interviews with external and internal parties from the digital and photography department. Next, in consultation with curator Louise Désy, a plan needed to be created, which first involved creating a workflow to better understand the process. This was finally to be followed by developing a guideline for description which included a list of fields that may be required to be handled differently than analogue photographs. It also includes recommendations for file transfers, metadata requirements, a guideline for donors, terms, and references. Lastly, a worksheet for data gathering and collection was created to aid any cataloguer to ensure uniformity in how data is collected.

\subsection{Interviews}

A total of nine people were interviewed for this project over a two-month period. They include from the CCA: Curator of photography, Louise Désy, Digitization Technician, Alan Reed, Digital archivists, Stefana Breitwieser and Alexandra Jokinen, photography conservator David Stevenson, and former CCA digital archivist, Tim Walsh. Interviewees from outside of the CCA are: photographer and CCA donor, Robert Burley; head of library and archives at the Art Gallery of Ontario, Amy Furness; and digital records archivist and special media archivist, Emily Sommers and Marnee Gamble from University of Toronto Archives \& Records Management Services 
(UTARMS). Each person was selected because they had hands-on experience with born-digital materials and/or had been instrumental in developing born-digital material protocols.

Due to the nature of this project an application to the Ryerson Ethics Board was submitted. Ultimately however, the project was exempt from needing approval. All of the documentation relating to the interviews can be found in Appendix $C$ of this document.

\subsubsection{Key Findings}

The aim of these interviews was to get a survey of the experience each professional had and continue to have in working with born-digital materials. As will be discussed further in this section, the interviews provided different avenues and areas of consideration when developing the guidelines. A variety of questions were asked. Some of the key questions range from:

- What is your role and what does it entail?

- Do you think it's important to have prints to accompany the digital files?

- What do you consider to be the original, the born-digital photographic file or the print?

- Can you speak to some of the workflows you use in processing and cataloguing borndigital materials?

- How were these workflows developed and how are they implemented?

- And lastly, can you speak about the kinds of metadata kinds that you use?

\section{Louise Désy}

Louise Désy, Curator of photography at the CCA, was instrumental in the development of the guideline. In the many conversations I had with her, we established a few areas that were of concern to her. The main issue was how to tackle the description of born-digital photographs in 
the database. The Museum System (TMS) is the system currently used at the CCA. The challenge and motivation of this project, in talking to Désy, became developing a standard in how fields in TMS would be used for born-digital photography.

\section{Stefana Breitwieser}

In speaking with a CCA archivist in the digital archive, Stefana Breitwieser, it became clear that an area of need and further investigation was metadata. She highlighted the challenge in trying to fit metadata into TMS descriptive standards, since TMS does not have a specific space for such information. "The metadata should dictate the system, the system should not dictate the metadata" (Breitwieser, interview) There are many metadata standards out there, but due to the variety of born-digital material with a range access restriction at the CCA the question become "how to shoehorn [metadata] into existing descriptions or expand existing standards to accommodate." (Breitwieser, interview) Furthermore, we discussed the challenge in the level of description that is needed to capture the breadth of a given born-digital object and how to manage how much of that information needs to be made available from an access point-of-view.

Another key notion Breitwieser addressed was in relation to access and issues in born-digital preservation that are more policy based rather than technological. Along with other archivists on her team, Breitwieser, is developing Scope which will be a platform for researchers to view borndigital materials in the CCA's reading room. In relation to this, she mentioned that at the CCA, digital materials are treated the same as archival material, as a result born-digital material will be only made available in the reading room. She recognised the paradox in this and commented that a selection of material is still made available online, however due to copyright and donor requirements not everything can be posted. This can be linked back to the challenge and need for revisions in documentation to better reflect born-digital archival and collections material. 


\section{David Stevenson}

CCA conservator David Stevenson and I spoke mostly about the early days of the digital department at the CCA. When Stevenson started at the CCA in 2011 the Centre was beginning to think about the project titled Archeology of the Digital and was looking into acquiring more borndigital material. Before his arrival there was group called Digital Archives Work Group (DAWG) which was number of people who worked at the CCA with an interest in digital. At that time, their focus was object-based, in that they were interested in media rather than systems. After his arrival, Stevenson along with three other collogues from different departments, started the Digital Knowledge Group (DKG), which met regularly and discussed the developments in digital archival materials. Through these meetings the need for software was the first thing they flagged, which was an important first consideration to make. In order to access born-digital materials it is important that the correct software is available. This has resulted in the CCA working diligently in acquiring software.

He mentioned an early, perhaps dated processing tool developed in house by IT. It became clear that there were better open source tools available and the DKG was given the mandate to test, document, and report back what they believed to be best for the CCA.

\section{Robert Burley}

Photographer, CCA donor and F+PPCM faculty, Robert Burley provided a lot of insight into the role of the creator and donor. He was also the perfect candidate since his 2017 body of work titled An Enduring Wilderness is in hybrid form, a part of the CCA photography collection and served as a key case study in the development of the guidelines. In talking to him I was curious to know what he considered the original iteration of a born-digital photographic work. This quandary is an important one since the issue of originality and authenticity is challenged when dealing with 
born-digital photography. He first discussed the importance of theorist Vilém Flusser's statement, "It is the apparatus that shapes the meaning of the image it produces...." and how his own photographic practice has been affected by this evolution to digital media. In the case of, $A n$ Enduring Wilderness Burley has donated 20 physical prints from this series along with 125 high resolution TIFF files to the CCA collection. The TIFF files are processed digital photographs that incorporate Burley's crops, adjustments and manipulations in the same way the prints do except these virtual images are intended to be accessed on a screen-based device. Burley spoke about the future of his RAW digital files that like photographic negatives act as the source for both the prints and TIFF files. He wondered if future advances in technology might create new ways to use and/or present these files. This notion of RAW files as negative is one I heard from a few other people I interviewed. It is also indicative of why it is best practice to collect TIFF files, aside from their stability as a file format. In a way, the TIFF file is similar to the printed image that would otherwise be physically added to a collection. Lastly, he also touched on the notion that most photographers are collections managers. This idea, in its simplicity, is very useful to keep in mind when thinking about how to approach donors of born-digital photograph, because again, it helps reiterate the need for collaboration.

\subsubsection{Business Workflows}

Following the interviews, the last step before creating the guidelines was the development of a workflow, which identified all the specific roles and the appropriate tasks associated with each stage of the process of the acquisition and cataloguing of born-digital photographs. Previously, there was no workflow on this procedure that captured the whole process. I felt it was important for a clear workflow so that new cataloguers would know exactly what the required steps are for 
the acquisition and cataloguing of born-digital photographs. Even though not all the areas relate to the cataloguer, it is crucial for them to know who to contact if questions about the process arise. Knowing what exactly I was responsible for what was another area that took some time for me to navigate as I was cataloguing at the CCA, the workflow is ultimately a tool to help eliminate any queries. Creating a workflow was also an exercise for me to better understand the required steps and the areas of that needed unpacking in the guideline. Moreover, the process helped each department really think about the steps they were already doing and how to streamline it. For example, the digital department and I went through numerous edits to find the most suitable order of steps that reflected what they were doing in the most efficient and accurate way.

Furthermore, to develop this, a few different workflows from other institutions were consulted, including an existing workflow from the digital department at the CCA. Stefana Breitwieser and Louise Désy were instrumental in reviewing and helping to revise the workflow to reflect the procedures already in place at the CCA. Ultimately it was decided that two workflows would better serve the process, titled CCA Workflow for Born-Digital Photography Accessioning and CCA Workflow for Born-Digital Photography Processing and Cataloguing (see appendix 1a and $1 \mathrm{~b}$ in Guidelines for Describing Born-Digital Photographs which is Appendix A of this document). 


\section{Guideline and Results}

The Guideline created here is specifically done so with the CCA in mind, however the aim is for other collections mangers, of varying collections sizes to be able to adapt the guideline to their needs. The focus of this project has been working specifically with tools for description and to aid in cataloguing born-digital photographs. The guideline also includes an Excel sheet that could act as an early stage database. It was created to be a space for a cataloguer to collect data before inputting it into the database. It includes all the relevant description fields and provides definitions and examples as they relate to born-digital photographs.

The main section of the guideline uses a simple table to break down four fields. These include: definition of the field, notes and example, the role of the individual responsible for populating the record and any other notes needed. In most cases, the "Notes" column includes a recommendation for the level of description (i.e. group and/or item) and as per best practice makes light of core fields. A new process at the CCA is to create group and item level records for the photography collection. As a result, it was important to include at what classification level information was to be captured for identification purposes.

\section{i. Physical Description}

\begin{tabular}{|c|c|c|c|}
\hline Definition & Notes and Example & Role & Notes \\
\hline $\begin{array}{l}\text { UC Guidelines for Born-Digital } \\
\text { Archival Description: Archival } \\
\text { Description and Extent: } \\
\text { Physical Description must include } \\
\text { units of measure for born-digital } \\
\text { material. This should always include } \\
\text { both the size of the digital material in } \\
\text { GB as well as the total number of } \\
\text { files that have been preserved } \\
\text { record a quantitative. }\end{array}$ & $\begin{array}{l}\text { - Use 'GB' ' instead of "Gigabytes", } \\
\text { "gigabyte", "Gb", "GBs", or any other } \\
\text { variations thereof. When calculating } \\
\text { size, round to three decimal points } \\
\text { only when content is less than } 1 \mathrm{~GB} \text {. If } \\
\text { content is smaller than } 1 \mathrm{MB} \text {, default } \\
\text { to ".001 GB". Otherwise, round to two } \\
\text { decimal points (ex. } 9.25 \mathrm{~GB}) . \text {. For } \\
\text { born digital photographs file size in } \\
\text { GB and total number of files }\end{array}$ & $\begin{array}{l}\text { photography } \\
\text { cataloguer }\end{array}$ & $\begin{array}{l}\text { Recommended } \\
\text { for TMS record } \\
\text { and } \\
\text { Archivematica } \\
\text { ingest } \\
\text { Populated at } \\
\text { group and item } \\
\text { level }\end{array}$ \\
\hline
\end{tabular}




\begin{tabular}{|l|l|l|}
\hline & $\begin{array}{l}\text { - This measurement should be recorded } \\
\text { separately from any Extent statement(s) } \\
\text { for physical material. Use parallel } \\
\text { Extent statements, if necessary. At } \\
\text { minimum, record the extent of digital } \\
\text { content in gigabytes (GB). } \\
\text { The number of files will also be recoded } \\
\text { in Object Count in TMS at group and } \\
\text { item level } \\
\text { Example: } \\
20 \text { printed photographs, 1GB, 125 } \\
\text { digital files }\end{array}$ \\
\hline
\end{tabular}

Figure 3 - Example of Born-Digital filed in the Guidelines. Page 7.

The main information in this section of the guideline is also re-visualized in Appendix 2. of the guideline titled "Recommendations for minimum requirements needed for TMS record and Archivematica ingest". This document was created based on two similar charts already in the documentation for the archives department and digital department at the CAA. (Name of documents: Fiche Modèle + Rubriques á compléter from CCA-Division Numérique, numérisation and Metadata recommendations for born-digital photograph collections material (2018-11-20)) The reason for this was to create a compact, handout style document that could easily be given to a cataloguer to consult as they work on cataloguing born-digital photographs.

A few areas in the guideline need further unpacking. Foremost are how specific fields are being captured in TMS. There are two sub-sections in the Description Fields portion of the guideline. The first is dedicated to those fields that may be different when cataloguing born-digital photographs. The second breaks down the fields that may or may not be mandatory at the CCA. 


\section{i. Technique, Medium and Photo Process}

\begin{tabular}{|c|c|c|c|}
\hline Definition & Notes and Example & Role & Notes \\
\hline $\begin{array}{l}\text { Dublin Core: Format: } \\
\text { The property format refers to the file } \\
\text { format, the physical medium (e.g. the } \\
\text { data storage medium), or the } \\
\text { dimension (the size or duration) of a } \\
\text { resource. The information can be } \\
\text { relevant to determine the equipment } \\
\text { needed to display or operate a } \\
\text { resource (e.g. if the described } \\
\text { resource has format pdf you need a } \\
\text { pdf reader to use it). To specify the } \\
\text { different categories of format you } \\
\text { should use extent and/or medium. To } \\
\text { reference the nature or genre of the }\end{array}$ & $\begin{array}{l}\text { Use AAT for correct vocabulary of file } \\
\text { formats and the Library of Congress } \\
\text { Format Descriptions for Still Images } \\
\text { http://www.getty.edu/research/tools/voca } \\
\text { bularies/aat/ } \\
\text { http://www.loc.gov/preservation/digital/fo } \\
\text { rmats/fdd/still_fdd.shtml } \\
\text { Example: } \\
\text { Group level or item level- hybrid collection } \\
\text { (print and digital image) } \\
\text { Pigmented Inkiet print, TIFF (8-bit, RGB) } \\
\text { Item level - born-digital photography } \\
\text { TIFF (8-bit, RGB) }\end{array}$ & $\begin{array}{l}\text { photography } \\
\text { cataloguer }\end{array}$ & $\begin{array}{l}\text { Mandatory for } \\
\text { TMS record } \\
\text { Populated at } \\
\text { group and item } \\
\text { level }\end{array}$ \\
\hline
\end{tabular}

Figure 4-Example of Born-Digital filed in the Guidelines. Page 5.

To understand how data is to be captured in TMS there needs to be a further unpacking of how information is presented in the Description Fields section of the guideline. Each description field provides a title and a four-column breakdown of how to catalogue born-digital photographs. The first column gives a definition of each field based on an existing description standard that takes into consideration cataloguing born digital archival material. The next column unpacks how born-digital photographs are to be treated. For example, in the case of the Title field there is a note on the distinction between file title and given title. The note in this section highlights the important distinction between the two and suggests how to record the different data in TMS. In some cases, there is also a note on what specific field should be used in TMS. This is important since not all the descriptions fields in the guideline have a designated space in TMS. Although at times these notes may seem straightforward and redundant it should not be lost on us that consistency is the name of the game when cataloguing and how data is collected and input into the database should be homogeneous. The next column is dedicated to the person responsible for the populating of this 
information. Although at this juncture, they are all the same at the CCA. It is important to note that if role distribution is different at other institutions, this column should be adapted to reflect whose responsibility it is to gather/verify data. Lastly, the notes column is earmarked for notes on where and in what case this field is mandatory to be populated. It also provides a note on what classification level the data should be input into TMS.

EXTIF Metadata is another area that needs some unpacking. Exchangeable Image File (EXTIF) metadata is a standard that is produced by the device that creates the digital file. In the case of born-digital photographs, it is the digital camera. It records and embeds information related to the camera model and settings (e.g. camera/lens/exposure information, time/date/, etc.) within the file. This information can also be populated by the creator of the images after the fact. It is a significant part of born-digital photography metadata because it is embedded in the image. This means that pertinent information is always with the digital file. This is significant for historians, curators and researchers, because information found in metadata has not been so easily accessible in the past. With that said, it is important to not forget that the verification of this information is critical, since making alterations is so easy to do. This guideline advises the use of Adobe Bridge as a tool to access and, with caution, revise EXTIF metadata. The International Press Telecommunication Council's (IPTC) Photo Metadata Working Group, has released the Cultural Heritage Metadata Plugin for Adobe Bridge, which allows one to extract EXTIF metadata into an Excel sheet. This is not included in the guideline since the CCA already has other tools in place to get this information. However, other institutions may find it extremely useful as it is free and easy to use. 
The research and interviews conducted for this case study call to attention the lack of information about metadata and specifically EXTIF metadata. It appears that everyone understands the importance of its inclusion, however there is no consensus on how to tackle collecting and representing it in databases. Ultimately the conclusion reached at the end of this case study is that it is important to collect EXTIF metadata from the donor, in whatever capacity they are willing to provide it. This guideline provides a suggested list that the institution should look for. The same list is also included as a suggestion in the Guideline for Donors. Since this information comes from the donor it is also important to talk to the donor and establish what is important to them and how embedded metadata relates to their specific project. In some cases, more metadata like geographical information may be useful to include, in others, this list may contain too many suggestions. The key is to communicate with the donor.

The Guideline for Donors is the Appendix 3. in the guideline. The aim of the Donor guideline is to ensure that works enter the collection in a consistent manner and that "all born-digital photographs are accompanied with appropriate information and documentation for understanding the context of their creation and use. And to include Embedded Metadata which supports discovery, management and reuse - usually a composite of management, descriptive, technical, rights and preservation metadata. (Spectrum digital asset management 2017)" (how to cite guideline?) It was important to me and Louise Désy that the donors were also addressed in the guidelines. Robert Burley has been a longtime donor at the CCA and is more recently including born-digital files as a part of his donations. In speaking to Burley, it became even more clear how essential it was to include the donors of born-digital photographs in the process of acquisition. The function of the document created for the CCA is twofold. On the one had its to ensure that the donor knows what is expected of them at the time of donation and to warrant a standard of how 
work is to be accepted at the CCA. Obviously, these requirements will be revised on a case by case basis because artists work differently, and the needs of artworks vary. The key however is that this guideline will allow for an introduction to a dialogue between collections managers and donors.

Lastly, once the guideline was completed I conducted a presentation for the involved parties to explain and breakdown the guideline. I explained the three key areas of the guideline which are: the development of a clear workflow of the how born-digital photographs enter and are processed into the collection; the establishment of a description standard where it was important to identify how the information gathered would differ from printed photographs, furthermore, how this information would be captured in TMS; and lastly, how to better understand embedded metadata and how to include it and make it accessible.

While the guideline aims to outline a precise and at times rigid set of rules for best practice, it should be remembered that these guidelines serve as recommendations and as a result the cataloguer, and institution by extension, should be flexible to review and revise this document as needed. 


\section{Conclusion}

The goal of this MRP has been to unpack the steps and considerations taken in creating a guideline for the cataloguing of born-digital photographs. Although the guidelines are based on a case study and a specific institution, my hope is that other professionals may be able to use this project as point of departure for their own collections. However, they should keep in mind that additional information on how to facilitate the technical aspects of collecting born-digital photographs will likely be required along the way. Even at the CCA the guideline needs to be tested by staff over an extended time period and this will undoubtedly lead to changes and perhaps more effective approaches to tackling this type of material in collections. Collections managers working with this guideline also need to adapt it to reflect their particular needs and the specificities of their born-digital photography collections. Furthermore, at the time of databases layout development there needs to be a consideration of how born-digital materials as whole are to be captured.

Overall the guideline created for the CCA was well received and everyone involved was excited about creating a new structure for born-digital photography collections. Unfortunately, due to the nature and time frame of this project there was no time to workshop the guidelines to other institutions for feedback. With that said, everyone that has been made aware of the project is excited to access and adapt it. Only time will tell how it will be received and used by other collections managers. As Jackie Dooley emphasizes in her $8^{\text {th }}$ Commandment for Special Collections Librarians in the Digital Age states "special collections staff often need not bear lead responsibility." (Dooley 2009, 57) Here I want to highlight the importance of collaboration, both 
within the institution and with the larger community and it will be fascinating to see how the guideline will develop and adapt as technology changes and people begin to use it.

This guideline is an important first step for a number of reasons. Primarily, since the metadata in born-digital material can so easily be altered and manipulated there needs to be a standardized method of approach that considers accountability and diligence in recording any interventions. This is a new factor for institutions which changes the nature of collections and therefore at the crux of the need for such a guideline. The goal being to ensure long-term preservation and access to born-digital photographs. As an example, a question arises about how to balance original and arranged order in documentation? And how to hold cataloguers and digital archivist accountable for their processing of this material? Ultimately each institution will tackle this differently, however, what is important is to have a benchmark of how to approach the problem.

Due to limits of time and resources there are areas that have not been addressed in this project but are nevertheless important considerations for future investigation. For example, the issue of database layout and organization that account specifically born-digital photographs and generally to born-digital material. Automatic vs manual data creation in fields has been somewhat addressed in this guideline. However, there is little mentioned from the perspective of access and accuracy. The development of a set of tools that allow for monitoring and flagging any areas of discrepancy would be an excellent next step. Lastly, a continuation of work on metadata is needed to better understand how to capture metadata as technologies advance. For example, the recent and ongoing developments in geotagging now employed by most digital camera systems. Tangentially there needs to be collaboration and work done to investigate and review the needs of researchers as they relate to how the current recorded metadata is holding up. 
6 Documentation

Appendix A - CCA Guidelines for Describing Born-Digital Photographs

\section{Guidelines for Describing Born-Digital Photographs Canadian Centre for Architecture}

Completed by:

Saba Moghtader

Collections Intern in the Photography Department

Ryerson University (Film and Photography Preservation and Collections Management) January 2019-June 2019 


\section{Table of contents}

1. Introduction 3

2. Description Fields 4-11

a. Specific to Born-Digital Photographs 4-9

b. Other Descriptive Fields $9-11$

3. EXTIF Metadata 12

$\begin{array}{ll}\text { 4. Image processing for TMS } & 13\end{array}$

5. Example of Records 14-15

6. Workflow 16

$\begin{array}{ll}\text { 7. Conclusion } & 17\end{array}$

8. Definition of Terms 18-20

$\begin{array}{ll}\text { 9. Bibliography 21-22 } & \end{array}$

$\begin{array}{lr}\text { Appendix 1. Workflow diagram } & 23-24\end{array}$

Appendix 2. Recommendations for minimum requirements 25-26 needed for TMS record and Archivematica ingest

Appendix 3. Guideline for Donors 27-28 


\section{Introduction:}

As the Canadian Centre for Architecture's (CCA) born-digital photography collections grow, so does the need for a more defined set of guidelines on the best practices of how to acquire, describe and preserve said photographs. This guideline is to assist photography cataloguers and collections managers at the different stages of born-digital photography processing in order to ensure continuity and parity between the description of their analogue and their born digital photography holdings in The Museum System (TMS).

This project was realized as part of a master's research project titled, Adapting to Born-Digital Photographs: A Case Study at Canadian Centre for Architecture. As the title suggests its aim was to adapt existing workflows and standards of the collection and preservation of born-digital materials to align with born-digital photographs to be included in a new revision of the cataloguing guidelines at the CCA.

It should be noted that this document should be revised and updated not only as the collection grows but also as the technology for this type of material develops and changes.

This guide is adapted from existing documentation at the CCA and from Best Guess Guidelines for Cataloguing Born Digital Material, UC Guidelines for Born-Digital Archival Description, Dublin Core, and the Getty Data Standards and Guidelines. Look for a completed bibliography and further readings the end of this document.

General Principles

- The aim of these guidelines is to provide advice on creating descriptions for born-digital photographs which employ a number of descriptive standards. As well as providing advice on where to find data in the collection's database.

- This document does not provide a complete list of all the metadata thought to be required in order to ensure the ongoing preservation of born digital photographs. Instead it provides a pared down list of the metadata that is intended to be a point of departure.

- As suggested by Best Guess Guidelines for Cataloguing Born Digital Material, the advent of born digital material and of new tools for its processing opens up the possibility for the automatic creation of description. As a general principle, it is considered important that researchers and users are made aware of the degree of human intervention in the information they are looking at, i.e. if a field has been populated automatically with no human intervention, this needs to be made clear. 


\section{Description Fields:}

\section{a. Specific to Born-Digital Photographs:}

\section{ii. Object Number}

\begin{tabular}{|l|l|l|l|}
\hline Definition & Notes and Example & Role & Notes \\
\hline Dublin Core: Identifier: & $\begin{array}{l}\text { Born digital photographs will be } \\
\text { catalogued at group and/or item level, } \\
\text { unless otherwise decided by the curator of } \\
\text { resource within a given context } \\
\text { a unique alpha-numeric identifier } \\
\text { assigned to an object or group of } \\
\text { objects. }\end{array}$ & $\begin{array}{l}\text { photography } \\
\text { cataloguer } \\
\text { The object number consists of a two-letter } \\
\text { collection code for photography (PH), year } \\
\text { of acquisition, a sequential number of } \\
\text { four digits from 0001-9999, with a } \\
\text { separate series for each collection, an } \\
\text { optional number or range of numbers } \\
\text { assigned to individual items within a } \\
\text { group }\end{array}$ & $\begin{array}{l}\text { Archivematica } \\
\text { ingest }\end{array}$ \\
& $\begin{array}{l}\text { Example: } \\
\text { PHYYY:SSS:NNN-NNN } \\
\text { PH2020:0004:001-035 }\end{array}$ & $\begin{array}{l}\text { group and item } \\
\text { level }\end{array}$ \\
\hline
\end{tabular}

\section{iii. Title}

\begin{tabular}{|c|c|c|c|}
\hline Definition & Notes and Example & Role & Notes \\
\hline $\begin{array}{l}\text { Dublin Core: Title: } \\
\text { Property that refers to the name or } \\
\text { names by which a resource is } \\
\text { formally known. In the case of } \\
\text { born-digital photographs } \\
\text { alternative titles may be recorded } \\
\text { as } \\
\text { Alternative title: property that } \\
\text { refers to a name or names of a } \\
\text { resource used as a substitute or } \\
\text { alternative to the formal title. }\end{array}$ & $\begin{array}{l}\text { Best guess guidelines for cataloguing born } \\
\text { digital materials } \\
\text { There is a distinction between file title and } \\
\text { a given title. In the case of file titles this } \\
\text { field can be autogenerated at the time of } \\
\text { ingest making the process more } \\
\text { streamlined, however file titles often do } \\
\text { not capture the depth of the object. } \\
\text { Both should be captured in TMS under the } \\
\text { title field. With title type identified as artist } \\
\text { title or constructed title and file name. }\end{array}$ & $\begin{array}{l}\text { photography } \\
\text { cataloguer }\end{array}$ & $\begin{array}{l}\text { Mandatory for } \\
\text { both TMS } \\
\text { record and } \\
\text { Archivematica } \\
\text { ingest } \\
\text { Populated at } \\
\text { group and item } \\
\text { level }\end{array}$ \\
\hline
\end{tabular}

\section{iv. Dates}

\begin{tabular}{|l|l|l|l|}
\hline Definition & Notes and Example & Role & Notes \\
\hline Dublin Core: Date: & $\begin{array}{l}\text { Born-digital photographs in a RAW or } \\
\text { DNG format can be considered the }\end{array}$ & $\begin{array}{l}\text { photography } \\
\text { cataloguer }\end{array}$ & $\begin{array}{l}\text { Mandatory for } \\
\text { both TMS }\end{array}$ \\
\hline
\end{tabular}




\begin{tabular}{|c|c|c|}
\hline $\begin{array}{l}\text { This property date refers to a } \\
\text { description of any data or ranges in } \\
\text { the lifecycle of resource and is } \\
\text { typically associated with the record } \\
\text { creation or availability. If the } \\
\text { distinction between different } \\
\text { categories of date is necessary, the } \\
\text { following sub properties should be } \\
\text { used. Created, Issued, Available, } \\
\text { Modified, Valid, Copyrighted, } \\
\text { Submitted, Accepted. }\end{array}$ & $\begin{array}{l}\text { same as a negative image and as such } \\
\text { the negative creation date is what will be } \\
\text { recorded in TMS, this date can be found } \\
\text { in the EXTIF metadata of the file and } \\
\text { automatically generated in METS } \\
\text { documentation created at the time of SIP } \\
\text { creation. } \\
\text { Other dates that can be useful to } \\
\text { capture are modified and print dates if } \\
\text { any. It is important to keep in mind that } \\
\text { the last modified date might not be } \\
\text { accurate or useful as it may reflect the } \\
\text { last software update and not the last } \\
\text { modification made on the image. }\end{array}$ & $\begin{array}{l}\text { record and } \\
\text { Archivematica } \\
\text { ingest } \\
\text { Populated at } \\
\text { group and item } \\
\text { level }\end{array}$ \\
\hline
\end{tabular}

\section{v. Classification}

\begin{tabular}{|l|l|l|l|}
\hline Definition & Notes and Example & Role & Notes \\
\hline $\begin{array}{l}\text { Getty Data Standards and } \\
\text { Guidelines: Catalog level 1.: }\end{array}$ & Example: & $\begin{array}{l}\text { photography } \\
\text { cataloguer }\end{array}$ & $\begin{array}{l}\text { Mandatory for } \\
\text { TMS record }\end{array}$ \\
$\begin{array}{l}\text { an indication of the level of } \\
\text { cataloguing represented by the } \\
\text { record, based on physical form or } \\
\text { intellectual content of the material. }\end{array}$ & Group, Piece & $\begin{array}{l}\text { Populated at } \\
\text { group and item } \\
\text { level }\end{array}$ \\
\hline
\end{tabular}

\section{vi. Technique, Medium and Photo Process}

\begin{tabular}{|c|c|c|c|}
\hline Definition & Notes and Example & Role & Notes \\
\hline $\begin{array}{l}\text { Dublin Core: Format: } \\
\text { The property format refers to the file } \\
\text { format, the physical medium (e.g. } \\
\text { the data storage medium), or the } \\
\text { dimension (the size or duration) of a } \\
\text { resource. The information can be } \\
\text { relevant to determine the equipment } \\
\text { needed to display or operate a } \\
\text { resource (e.g. if the described } \\
\text { resource is in a Portable Document } \\
\text { Format (PDF) you need a PDF } \\
\text { Reader to use it). To specify the } \\
\text { different categories of format you } \\
\text { should use extent and/or medium. } \\
\text { To reference the nature or genre of } \\
\text { the content use type. }\end{array}$ & $\begin{array}{l}\text { Use AAT for correct vocabulary of file } \\
\text { formats and the Library of Congress } \\
\text { Format Descriptions for Still Images } \\
\frac{\text { http://www.getty.edu/research/tools/voc }}{\text { abularies/aat/ }} \\
\frac{\text { http://www.loc.gov/preservation/digital/ }}{\text { formats/fdd/still fdd.shtml }} \\
\text { Example: } \\
\text { Group level or item level- hybrid } \\
\text { collection (print and digital image) } \\
\text { Pigmented Inkjet print, TIFF (8-bit, RGB) } \\
\text { Item level - born-digital photography } \\
\text { TIFF (8-bit, RGB) }\end{array}$ & $\begin{array}{l}\text { photography } \\
\text { cataloguer }\end{array}$ & $\begin{array}{l}\text { Mandatory for } \\
\text { TMS record } \\
\text { Populated at } \\
\text { group and item } \\
\text { level }\end{array}$ \\
\hline
\end{tabular}




\section{vii. Dimensions}

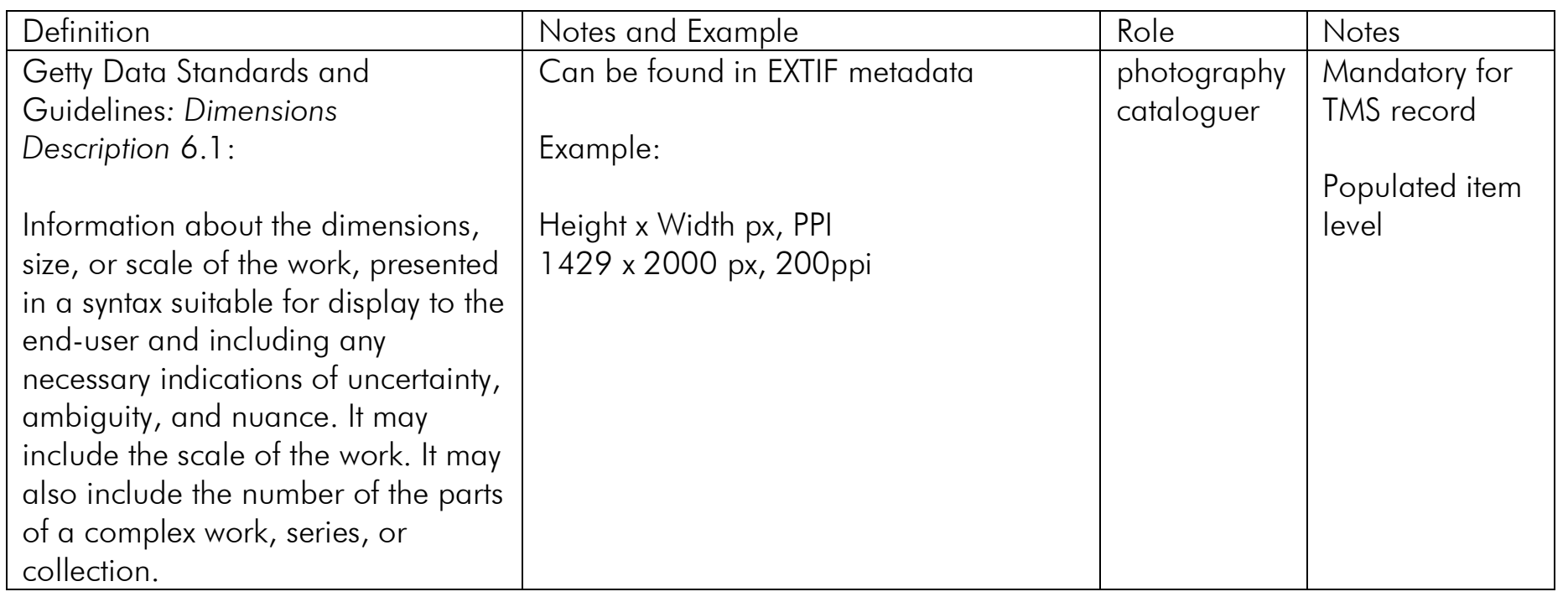

\section{viii. Source of Acquisition}

\begin{tabular}{|c|c|c|c|}
\hline Definition & Notes and Example & Role & Notes \\
\hline $\begin{array}{l}\text { UC Guidelines for Born-Digital } \\
\text { Archival Description: Immediate } \\
\text { source of Acquisition: } \\
\text { Record general information about } \\
\text { the acquisition of born-digital } \\
\text { material, such as the source, date, } \\
\text { and type of acquisition, in an } \\
\text { Immediate Source of Acquisition } \\
\text { Note. However, since acquisition of } \\
\text { born-digital content often involves } \\
\text { technical processing and data } \\
\text { capture after media has been } \\
\text { physically transferred, the specific } \\
\text { methods and processes of born- } \\
\text { digital acquisition and data capture } \\
\text { should be detailed in a Processing } \\
\text { Information Note. Refer to the } \\
\text { Processing Information section in } \\
\text { this document. Do not enter specific } \\
\text { technical details in Immediate } \\
\text { Source of Acquisition. }\end{array}$ & $\begin{array}{l}\text { This information can be captured in the } \\
\text { excel worksheet in one place. In TMS } \\
\text { however it appears in a few places, with } \\
\text { some needing to be populated and } \\
\text { other autogenerating. } \\
\text { Example in Excel worksheet: } \\
\text { The } 125 \text { digital files from The Enduring } \\
\text { Wilderness series were donated to the } \\
\text { CCA by Robert Burley on January } 21 \text {, } \\
2018 \text { as TIFF Files through WeTransfer. } \\
\text { (Populated at group level) } \\
\text { Examples and location in TMS: } \\
\text { The date of accession is captured in } \\
\text { registration (drop down)- accessioning - } \\
\text { under accession date } \\
\text { The donation source will be captured in } \\
\text { constituents. } \\
\text { Information about the timeline of } \\
\text { information populated in TMS is } \\
\text { autogenerated under maintenance (drop } \\
\text { down) - audit trail }\end{array}$ & $\begin{array}{l}\text { photography } \\
\text { cataloguer }\end{array}$ & $\begin{array}{l}\text { Recommended, } \\
\text { not mandatory } \\
\text { for TMS and } \\
\text { Archivematica }\end{array}$ \\
\hline
\end{tabular}


(Populated at group and item level)

\section{ix. Physical Description}

\begin{tabular}{|c|c|c|c|}
\hline Definition & Notes and Example & Role & Notes \\
\hline $\begin{array}{l}\text { UC Guidelines for Born-Digital } \\
\text { Archival Description: Archival } \\
\text { Description and Extent: } \\
\text { Physical Description must include } \\
\text { units of measure for born-digital } \\
\text { material. This should always include } \\
\text { both the size of the digital material } \\
\text { in GB as well as the total number of } \\
\text { files that have been preserved } \\
\text { record a quantitative. }\end{array}$ & $\begin{array}{l}\text { - Use 'GB' ' instead of "Gigabytes", } \\
\text { "gigabyte", "Gb", "GBs", or any other } \\
\text { variations thereof. When calculating } \\
\text { size, round to three decimal points } \\
\text { only when content is less than } 1 \mathrm{~GB} \text {. If } \\
\text { content is smaller than } 1 \mathrm{MB} \text {, default } \\
\text { to ".001 GB". Otherwise, round to } \\
\text { two decimal points (ex. } 9.25 \mathrm{~GB}) . \text { " For } \\
\text { born digital photographs file size in } \\
\text { GB and total number of files } \\
\text { - This measurement should be recorded } \\
\text { separately from any Extent statement(s) } \\
\text { for physical material. Use parallel } \\
\text { Extent statements, if necessary. At } \\
\text { minimum, record the extent of digital } \\
\text { content in gigabytes (GB). } \\
\text { The number of files will also be recoded } \\
\text { in Object Count in TMS at group and } \\
\text { item level } \\
\text { Example: } \\
20 \text { printed photographs, } 1 G B, 125 \\
\text { digital files }\end{array}$ & $\begin{array}{l}\text { photography } \\
\text { cataloguer }\end{array}$ & $\begin{array}{l}\text { Recommended } \\
\text { for TMS record } \\
\text { and } \\
\text { Archivematica } \\
\text { ingest } \\
\text { Populated at } \\
\text { group and item } \\
\text { level }\end{array}$ \\
\hline
\end{tabular}

\section{x. Content Description}

\begin{tabular}{|c|c|c|c|}
\hline Definition & Notes and Example & Role & Notes \\
\hline $\begin{array}{l}\text { Traditionally Content Description is } \\
\text { a free text field that provides an } \\
\text { account of the item. In addition to } \\
\text { contextual information about the } \\
\text { items in the case of born-digital } \\
\text { photographs this field will also } \\
\text { include notes on Arrangement and } \\
\text { Technical Requirement. }\end{array}$ & $\begin{array}{l}\text { Refer to 1.x. Arrangement. } \\
\text { Example: } \\
\text { A group of } 125 \text { digital images files } \\
\text { embedded with metadata and } 20 \\
\text { printed photographs from the group. } \\
\text { The digital files were sent via } \\
\text { "WeTransfer". With minimal intervention } \\
\text { by the cataloguer the images where } \\
\text { organized and renamed to reflect their } \\
\text { associated object number and ingested } \\
\text { into Archivematica on February } 11 \text {, } \\
2019\end{array}$ & $\begin{array}{l}\text { photography } \\
\text { cataloguer }\end{array}$ & $\begin{array}{l}\text { Recommended } \\
\text { for TMS record } \\
\text { and mandatory } \\
\text { of } \\
\text { Archivematica } \\
\text { Populated at } \\
\text { group level }\end{array}$ \\
\hline
\end{tabular}




\begin{tabular}{|l|l|l|}
\hline & An Enduring Wilderness: Toronto's \\
Natural Parklands in a series & commissioned in 2012 by the City of \\
coronto that chronicles the extensive & Torive \\
ravine network of sunken rivers, forested & vales, and an extensive shoreline of \\
Toronto, which has been historically & overlooked, neglected, or forgotten. \\
Robert Burley looks at these sited as & integral parts of urban life, from lake \\
views of the Scarborough bluffs to & glimpses of the densely wooded tails in \\
the Carolinian forests of Rouge Park, & questioning their role in a diverse and \\
growing twenty-first century city. & \\
\hline
\end{tabular}

\section{xi. Arrangement}

\begin{tabular}{|c|c|c|c|}
\hline Definition & Notes and Example & Role & Notes \\
\hline $\begin{array}{l}\text { Best Guess Guidelines for } \\
\text { Cataloguing Born Digital Material } \\
\text { (BGG): 3.3.4: } \\
\text { For born digital material which has } \\
\text { been 'arranged', e.g. into a folder } \\
\text { structure, a decision will need to be } \\
\text { taken as to the extent to which this } \\
\text { folder structure should or should not } \\
\text { be replicated as levels of } \\
\text { arrangement/ description }\end{array}$ & $\begin{array}{l}\text { This will be recorded in the Content } \\
\text { Description field in TMS } \\
\text { BGG suggests if files have been } \\
\text { arranged by processor be sure to include } \\
\text { a description of any major } \\
\text { rearrangements from the original } \\
\text { arrangement of tiles. Rearrangements } \\
\text { can range from changes in file name to } \\
\text { changes to structure. Use the following } \\
\text { scenarios, as outlined by the BGG of } \\
\text { different degrees of intervention and } \\
\text { arrangement and elaborate as } \\
\text { necessary. } \\
\text { 1) No intervention by the archivist } \\
\text { 2) Minimal intervention by the archivist } \\
\text { 3) Intervention by the archivist } \\
\text { 4) Post-ingest intervention }\end{array}$ & $\begin{array}{l}\text { photography } \\
\text { cataloguer }\end{array}$ & $\begin{array}{l}\text { Recommended } \\
\text { for TMS record } \\
\text { Populated at } \\
\text { group level }\end{array}$ \\
\hline
\end{tabular}

\section{xii. Technical Requirements}

\begin{tabular}{|l|l|l|l|}
\hline Definition & Notes and Example & Role & Notes \\
\hline $\begin{array}{l}\text { UC Guidelines for Born-Digital } \\
\text { Archival Description: Technical } \\
\text { Requirements: }\end{array}$ & $\begin{array}{l}\text { This will be recorded in the Physical } \\
\text { Description field in TMS }\end{array}$ & $\begin{array}{l}\text { photography } \\
\text { cataloguer }\end{array}$ & $\begin{array}{l}\text { Recommended } \\
\text { on a case by } \\
\text { case basis }\end{array}$ \\
$\begin{array}{l}\text { Use this field to inform researchers } \\
\text { about the physical or technical }\end{array}$ & $\begin{array}{l}\text { A list of required hardware/software to } \\
\text { access born-digital files in a collection } \\
\text { may be useful to researchers, and even }\end{array}$ & & $\begin{array}{l}\text { Populated at } \\
\text { group level }\end{array}$ \\
\hline
\end{tabular}


characteristics of digital materials that will affect their ability to access them. This is especially important for open-access collections in which users may want to interact with digital materials on their own home computers, or in cases where the storage media or format cannot be made accessible on library computers. to reading room staff. If a particular collection requires certain tools to access content, however rarely, it should be noted. A list of the required software to access the born-digital files in a collection will allow the user to determine whether or not they can access materials at home (for open collections) or will need to access them in a reading room. Note whether or not the library has the necessary software to access all files.

\section{xiii. Processor}

\begin{tabular}{|l|l|l|l|}
\hline Definition & Notes and Example & Role & Notes \\
\hline $\begin{array}{l}\text { UC Guidelines for Born-Digital } \\
\text { Archival Description: }\end{array}$ & Autogenerated by TMS & $\begin{array}{l}\text { Photography } \\
\text { cataloguer }\end{array}$ & Recommended \\
$\begin{array}{l}\text { If the digital materials were } \\
\text { processed either at a later date } \\
\text { and/or by a different person than } \\
\text { the rest of the collection, specify } \\
\text { when and by whom they were } \\
\text { processed. }\end{array}$ & $\begin{array}{l}\text { Excel worksheet. } \\
\text { Exoced to make note of person }\end{array}$ & & $\begin{array}{l}\text { Populated at } \\
\text { group and item } \\
\text { level }\end{array}$ \\
\hline
\end{tabular}

\section{xiv. Conditions Governing Access and Restrictions}

\begin{tabular}{|l|l|l|l|}
\hline Definition & Notes and Example & Role & Notes \\
\hline DACS 4.1: & $\begin{array}{l}\text { This will be recorded in the Copyright } \\
\text { (Under rights \& Reproductions) field in } \\
\text { TMS }\end{array}$ & $\begin{array}{l}\text { Photography } \\
\text { cataloguer }\end{array}$ & $\begin{array}{l}\text { Mandatory if } \\
\text { applicable }\end{array}$ \\
$\begin{array}{l}\text { This element provides information access restrictions due to the } \\
\text { nature of the information in the } \\
\text { materials being described, such as } \\
\text { those imposed by the donor, by the } \\
\text { repository, or by statutory/regulatory } \\
\text { requirements. }\end{array}$ & & & $\begin{array}{l}\text { Populated at } \\
\text { group and item } \\
\text { level }\end{array}$ \\
\hline
\end{tabular}

\section{b. Other Descriptive Fields i. Constituents}

\begin{tabular}{|c|c|c|c|}
\hline Definition & Notes and Example & Role & Notes \\
\hline $\begin{array}{l}\text { Dublin Core: creator: } \\
\text { An entity primarily responsible for } \\
\text { makina the content of the resource. }\end{array}$ & $\begin{array}{l}\text { Getty Data standards and guidelines: } 4 . \\
\text { Creation: }\end{array}$ & $\begin{array}{l}\text { Photography } \\
\text { cataloguer }\end{array}$ & $\begin{array}{l}\text { Mandatory for } \\
\text { TMS record and } \\
\text { Archivematica } \\
\text { ingest }\end{array}$ \\
\hline
\end{tabular}


Examples of a creator include a person, an organization, or a service. Typically, the name of the creator should be used to indicate the entity.
Provides a detailed outline of core elements and examples.

In regard to born-digital photographs like analogue images at the CCA it is important to record the content creator, acquisition source and any other notable constituents associated to the item.
Populated at group and item level

\section{ii. Credit Line}

\begin{tabular}{|c|c|c|c|}
\hline Definition & Notes and Example & Role & Notes \\
\hline $\begin{array}{l}\text { Getty Data standards and } \\
\text { guidelines: Copyright/ Restrictions: } \\
\text { 22.0: } \\
\text { An identification of the individual or } \\
\text { group that holds the rights to use, } \\
\text { exhibit, or reproduce a work along } \\
\text { with an indication of any existing } \\
\text { restrictions on its reproduction, } \\
\text { exhibition, or use. }\end{array}$ & $\begin{array}{l}\text { Based on the CCA collections } \\
\text { documentation guide The credit line will } \\
\text { also reflect the wording by which the } \\
\text { institution, lender, donor or purchase } \\
\text { fund wishes to be acknowledged. } \\
\text { Example: } \\
\text { Collection Centre Canadien } \\
\text { d'Architecture/ } \\
\text { Canadian Centre for Architecture, } \\
\text { Montréal } \\
\text { Don de l'artiste/ Gift of the artist }\end{array}$ & $\begin{array}{l}\text { Photography } \\
\text { cataloguer }\end{array}$ & $\begin{array}{l}\text { Mandatory for } \\
\text { TMS record and } \\
\text { recommended } \\
\text { for } \\
\text { Archivematica } \\
\text { ingest } \\
\text { Populated at } \\
\text { group and item } \\
\text { level }\end{array}$ \\
\hline
\end{tabular}

\section{iii. Copyright}

\begin{tabular}{|c|c|c|c|}
\hline Definition & Notes and Example & Role & Notes \\
\hline $\begin{array}{l}\text { Getty Data standards and } \\
\text { guidelines: Copyright Statement: } \\
22.1 \text { : } \\
\text { A formal statement of the copyright } \\
\text { of a work, and/or any restrictions } \\
\text { placed on it. } \\
22.0 \text { : } \\
\text { A formal statement of the copyright } \\
\text { of a work, and/or any restrictions } \\
\text { placed upon it }\end{array}$ & $\begin{array}{l}\text { This will be recorded in the Copyright } \\
\text { (Under rights \& Reproductions) in TMS } \\
\text { This field is dedicated for credit to the } \\
\text { creator and any restriction placed on the } \\
\text { born-digital image. } \\
\text { Example: } \\
\text { CRobert Burley }\end{array}$ & $\begin{array}{l}\text { Photography } \\
\text { cataloguer }\end{array}$ & $\begin{array}{l}\text { Mandatory for } \\
\text { TMS record and } \\
\text { recommended } \\
\text { for } \\
\text { Archivematica } \\
\text { ingest } \\
\text { Populated at } \\
\text { group and item } \\
\text { level }\end{array}$ \\
\hline
\end{tabular}

\section{iv. Object Status}


TMS core files:

This field identifies the status of an object in the collection.
Controlled list in TMS:

Drop down list in TMS. Most common used from controlled vocabulary are Acquis - if the deed of gift has been signed

or

En depot - used for material on consignment

This field will be revised as the record is evolves

\begin{tabular}{l|l|}
$\begin{array}{l}\text { Registrar or } \\
\text { collections } \\
\text { technician }\end{array}$ & $\begin{array}{l}\text { Mandatory for } \\
\text { TMS record } \\
\text { Populated at } \\
\text { group and item } \\
\text { level }\end{array}$ \\
\end{tabular}

\section{v. Status Flag}

\begin{tabular}{|c|c|c|c|}
\hline Definition & Notes and Example & Role & Notes \\
\hline $\begin{array}{l}\text { TMS core files: } \\
\text { This field identifies the status at } \\
\text { which the record has been } \\
\text { catalogued and what function it } \\
\text { serves. }\end{array}$ & $\begin{array}{l}\text { Controlled list in TMS: most common } \\
\text { used are accession record, identification, } \\
\text { catalogued record, record for } \\
\text { management need } \\
\text { This field will be revised as the record is } \\
\text { populated and made available to } \\
\text { researchers }\end{array}$ & $\begin{array}{l}\text { Photography } \\
\text { cataloguer }\end{array}$ & $\begin{array}{l}\text { Mandatory for } \\
\text { TMS record } \\
\text { Populated at } \\
\text { group and item } \\
\text { level }\end{array}$ \\
\hline
\end{tabular}

\section{vi. Department}

\begin{tabular}{|l|l|l|l|}
\hline Definition & Notes and Example & Role & Notes \\
\hline TMS core files & $\begin{array}{l}\text { Controlled list in TMS: Archive, } \\
\text { Photographs, Prints \& Drawings. } \\
\text { In the case of born-digital photographs, } \\
\text { This field identifies the department } \\
\text { in which the object is accessioned } \\
\text { into. }\end{array}$ & $\begin{array}{l}\text { Photography } \\
\text { cataloguer }\end{array}$ & $\begin{array}{l}\text { Mandatory for } \\
\text { TMS record }\end{array}$ \\
& & $\begin{array}{l}\text { Populated at } \\
\text { group and item } \\
\text { level }\end{array}$ \\
\hline
\end{tabular}

\section{vii. Object Count}

\begin{tabular}{|l|l|l|l|}
\hline Definition & Notes and Example & Role & Notes \\
\hline TMS core files & Refer to 1. viii. Physical Description & $\begin{array}{l}\text { Photography } \\
\text { cataloguer }\end{array}$ & $\begin{array}{l}\text { Mandatory for } \\
\text { TMS record }\end{array}$ \\
$\begin{array}{l}\text { This field identifies the number of } \\
\text { objects in a given record. }\end{array}$ & & $\begin{array}{l}\text { Populated at } \\
\text { group and item } \\
\text { level }\end{array}$ \\
\hline
\end{tabular}

\section{viii. Object type}




\begin{tabular}{|c|c|c|c|}
\hline $\begin{array}{l}\text { Dublin Core: Type: } \\
\text { Refers to a description of the nature } \\
\text { or genre of the content of a } \\
\text { resource (e.g. a stylistic category, a } \\
\text { function or an aggregation level). } \\
\text { To describe the physical or digital } \\
\text { manifestation, use format. }\end{array}$ & $\begin{array}{l}\text { This will be recorded in the object type } \\
\text { (Under Attributes) in TMS }\end{array}$ & $\begin{array}{l}\text { Photography } \\
\text { cataloguer }\end{array}$ & $\begin{array}{l}\text { Mandatory for } \\
\text { TMS record and } \\
\text { optional for } \\
\text { Archivematica } \\
\text { ingest } \\
\text { Populated at } \\
\text { item level }\end{array}$ \\
\hline
\end{tabular}

\section{ix. Object name}

\begin{tabular}{|l|l|l|l|}
\hline Definition & Notes and Example & Role & Notes \\
\hline $\begin{array}{l}\text { Getty Data standards and } \\
\text { guidelines: Classification:2.0: }\end{array}$ & $\begin{array}{l}\text { Enter the type of object used using one } \\
\text { of the terms in French or in English }\end{array}$ & $\begin{array}{l}\text { Photography } \\
\text { cataloguer }\end{array}$ & $\begin{array}{l}\text { Mandatory for } \\
\text { TMS record }\end{array}$ \\
$\begin{array}{l}\text { Placement of a work of art within a } \\
\text { classification scheme that groups } \\
\text { other, similar works together on the } \\
\text { basis of similar characteristics }\end{array}$ & Example: & photograph(s) & $\begin{array}{l}\text { Populated at } \\
\text { group and item } \\
\text { level }\end{array}$ \\
\hline
\end{tabular}




\section{EXTIF Metadata}

EXTIF metadata will be provided by the donor and can be accessed through Adobe Bridge. It will also be made available at the time of SIP creation. It is recommended information that should be record in the Excel worksheet. As of now there is no need or designated place in TMS for this data. However, there may come a time that this information may need to be added to the TMS record. It is recommended that a field (perhaps inscription) be designated for this data. Here is a list of metadata recommended for donors to embed in their images.

$\begin{aligned} \text { i. } & \text { File Name } \\ \text { ii. } & \text { Date Created } \\ \text { iii. } & \text { Dimensions } \\ \text { iv. } & \text { Resolution } \\ \text { v. } & \text { Bit Depth } \\ \text { vi. } & \text { Color Mode } \\ \text { vii. } & \text { Color Profile } \\ \text { viii. } & \text { Exposure Mode } \\ \text { ix. } & \text { Focal Length } \\ \text { x. } & \text { ISO Speed } \\ \text { xi. } & \text { Flash } \\ \text { xii. } & \text { Shutter Speed Value } \\ \text { xiii. } & \text { Aperture Value } \\ \text { xiv. } & \text { Metering Mode } \\ \text { xv. } & \text { Camera Model }\end{aligned}$

Example of metadata found in Adobe Bridge:

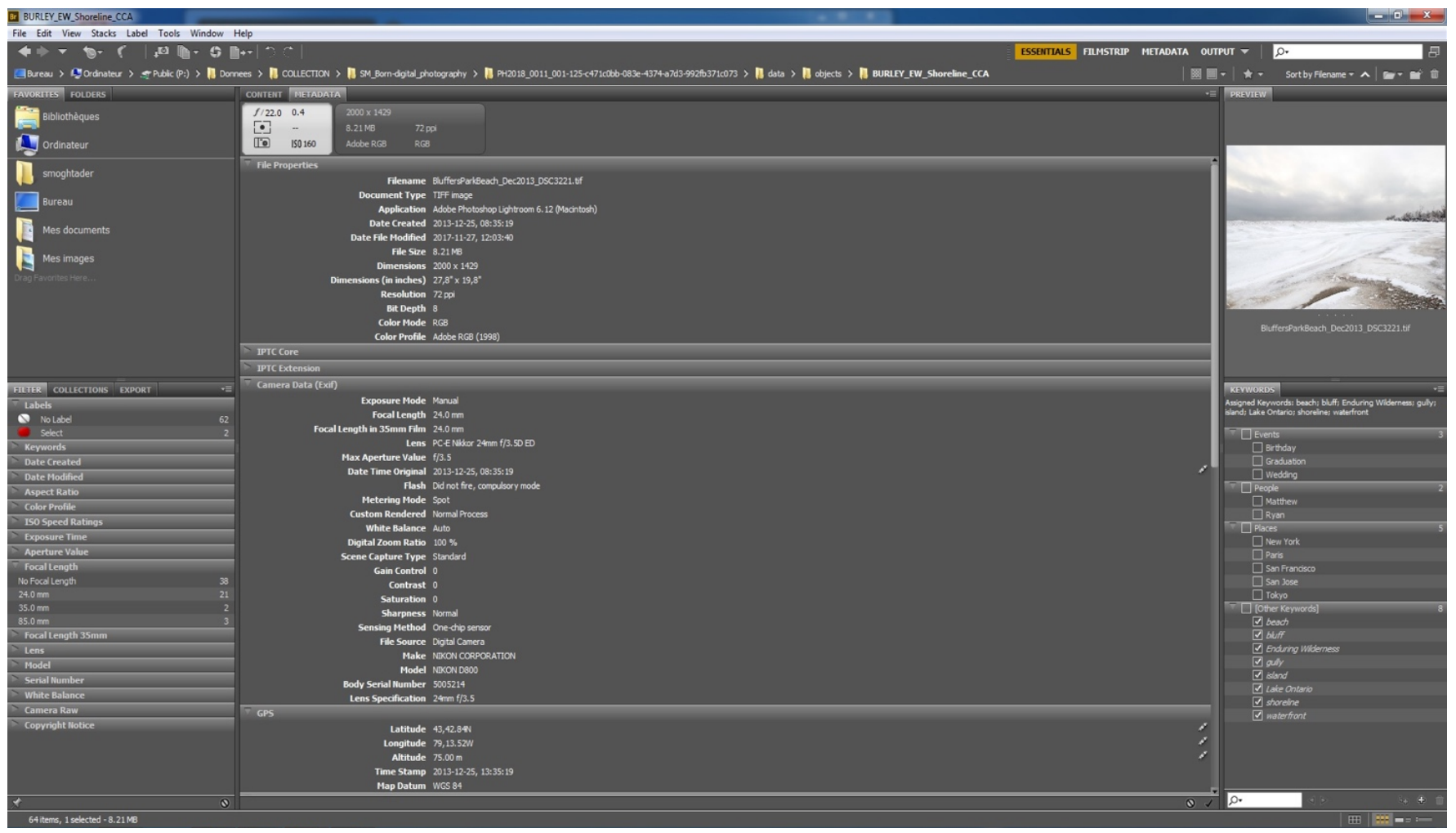




\section{Image processing for TMS - photographer or coordinator}

Normalization of Image files to be uploaded onto TMS for web search accessibility will need to be:

File format: JPEG

File size: will depend on the image

File dimensions: should be the same pixel dimension as the TIFF file

File naming: object number with ' ' used instead of ':' and '.'

e.g. PH2020_0004_001_035 


\section{Example of Record in TMS}

Group level PH2018:001 1:001-125 - auto view - to be used by photography cataloguer to input data into TMS

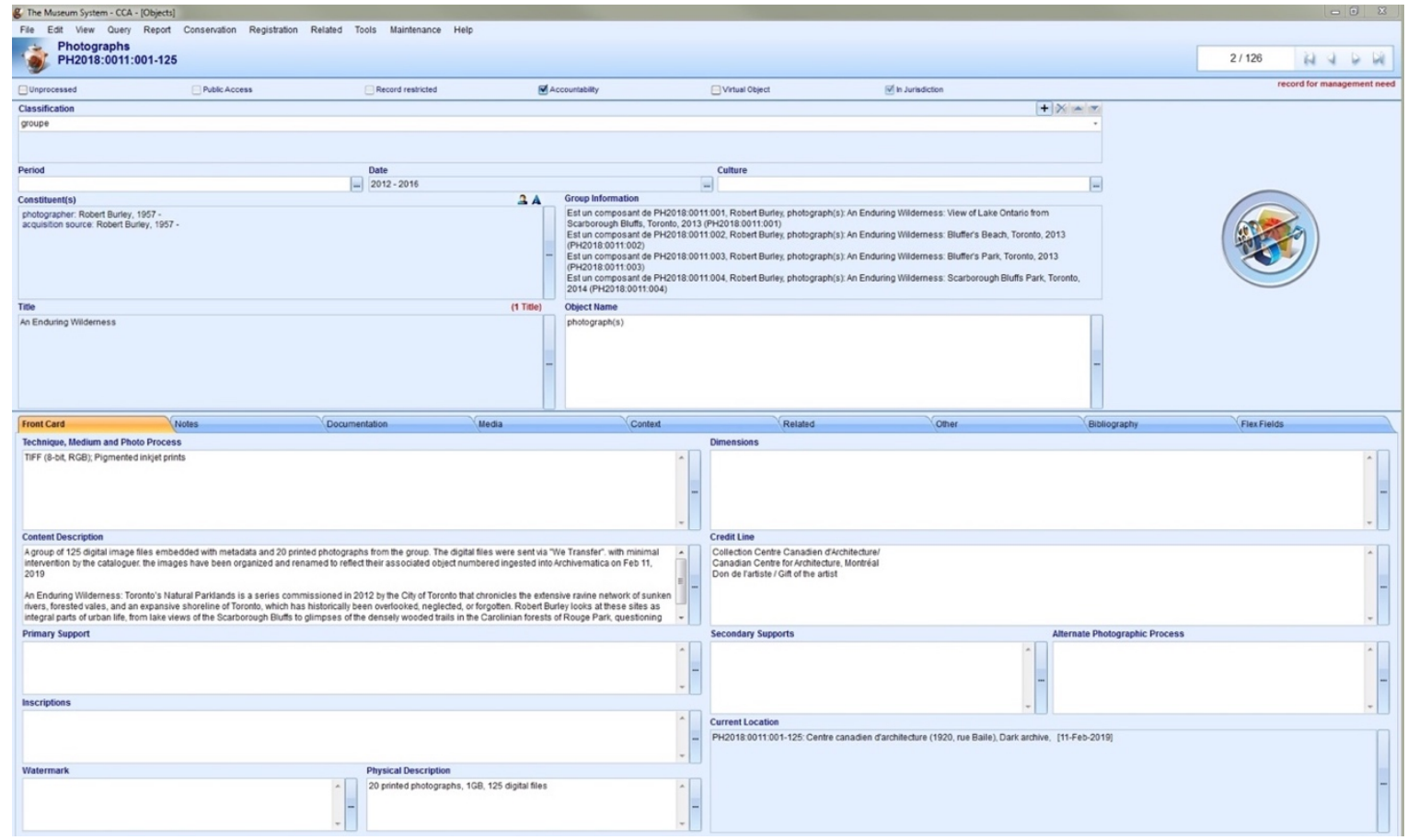

Group level PH2018:001 1:001-125 - archive data entry view - this view is to illustrate and help locate all the fields in this guideline

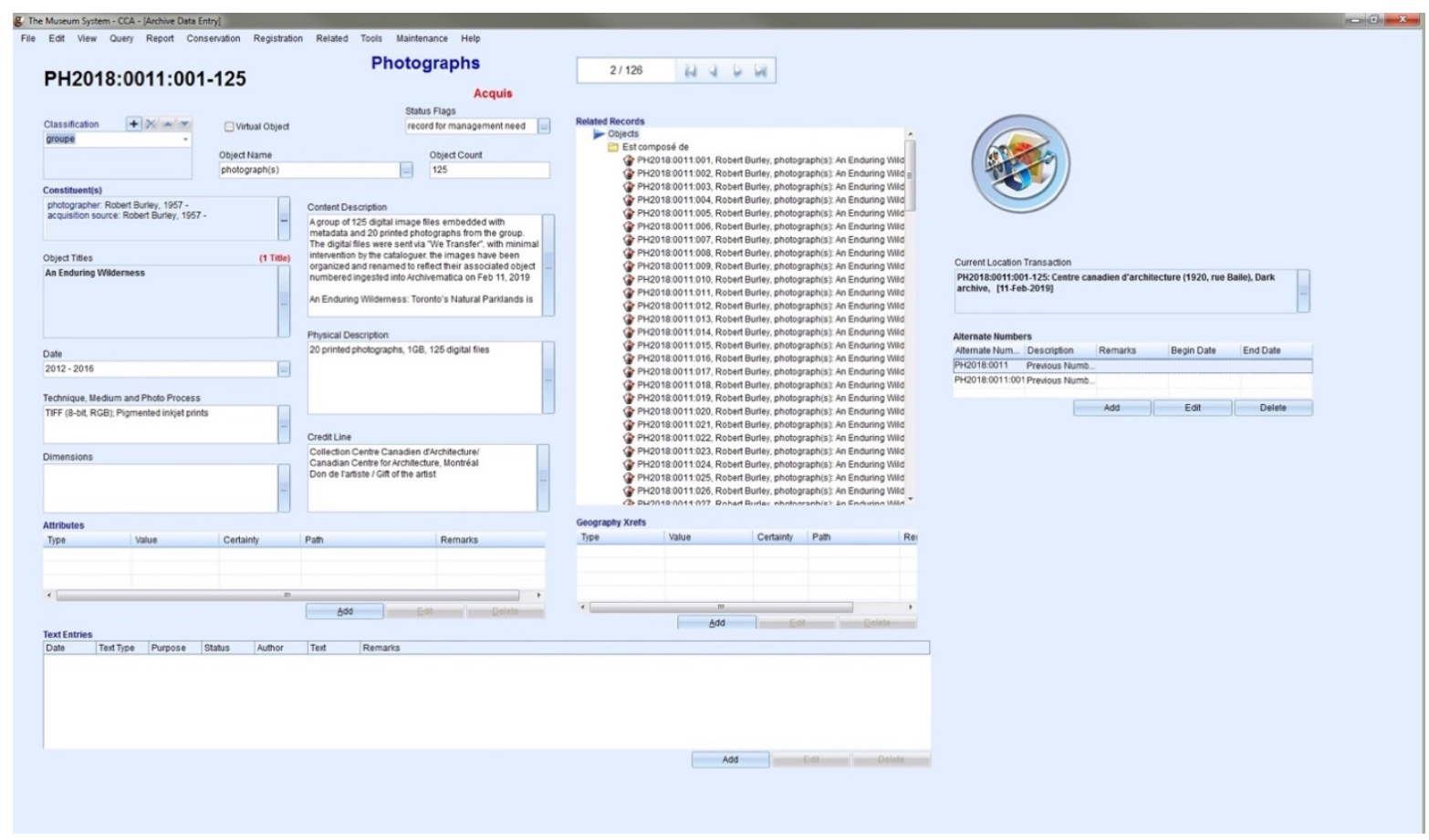


Item level PH2018:001 1:001 - auto view - to be used by photography cataloguer to input data into TMS

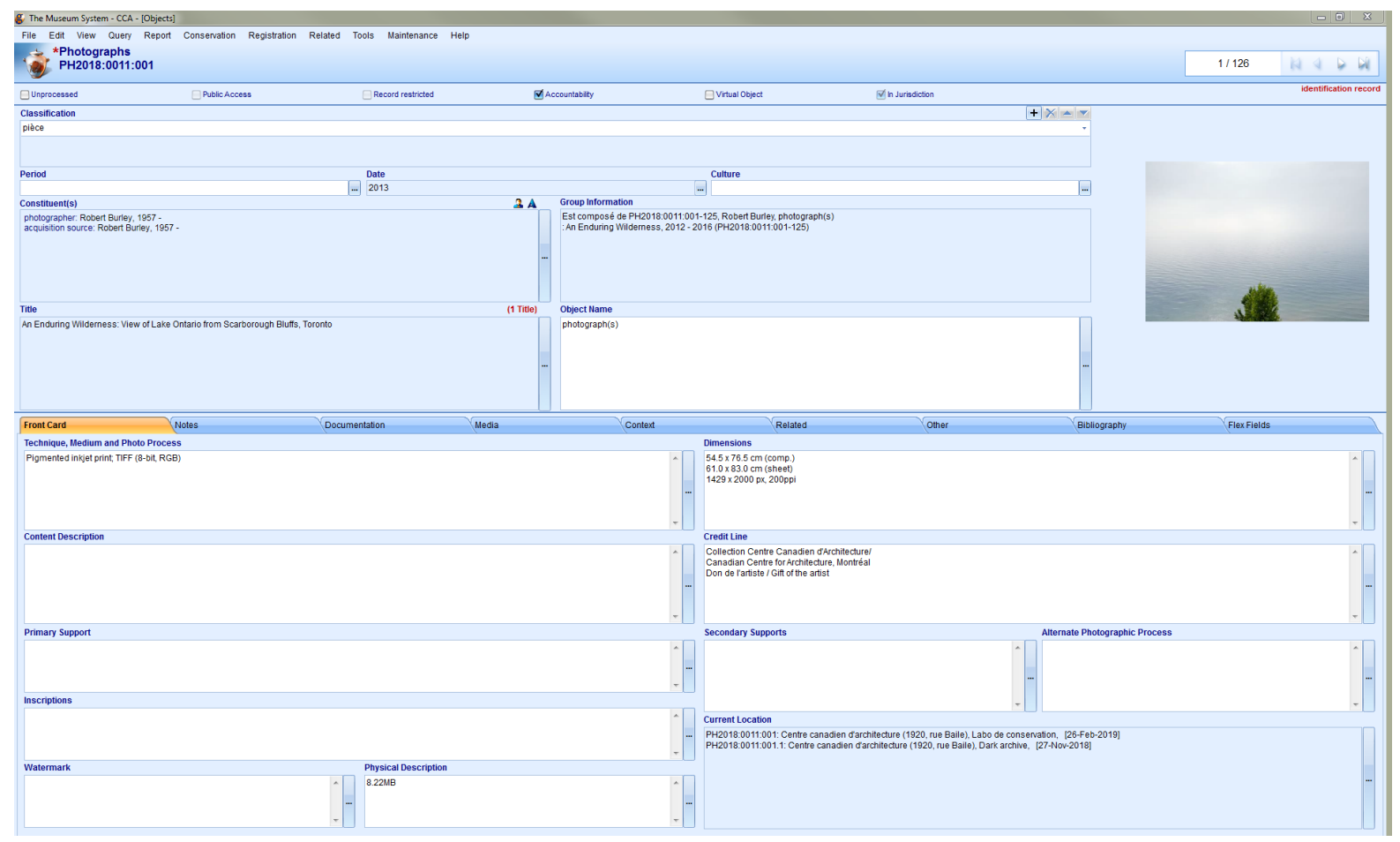

Item level PH2018:001 1:001-125 - archive data entry view - this view is to illustrate and help locate all the fields in this guideline

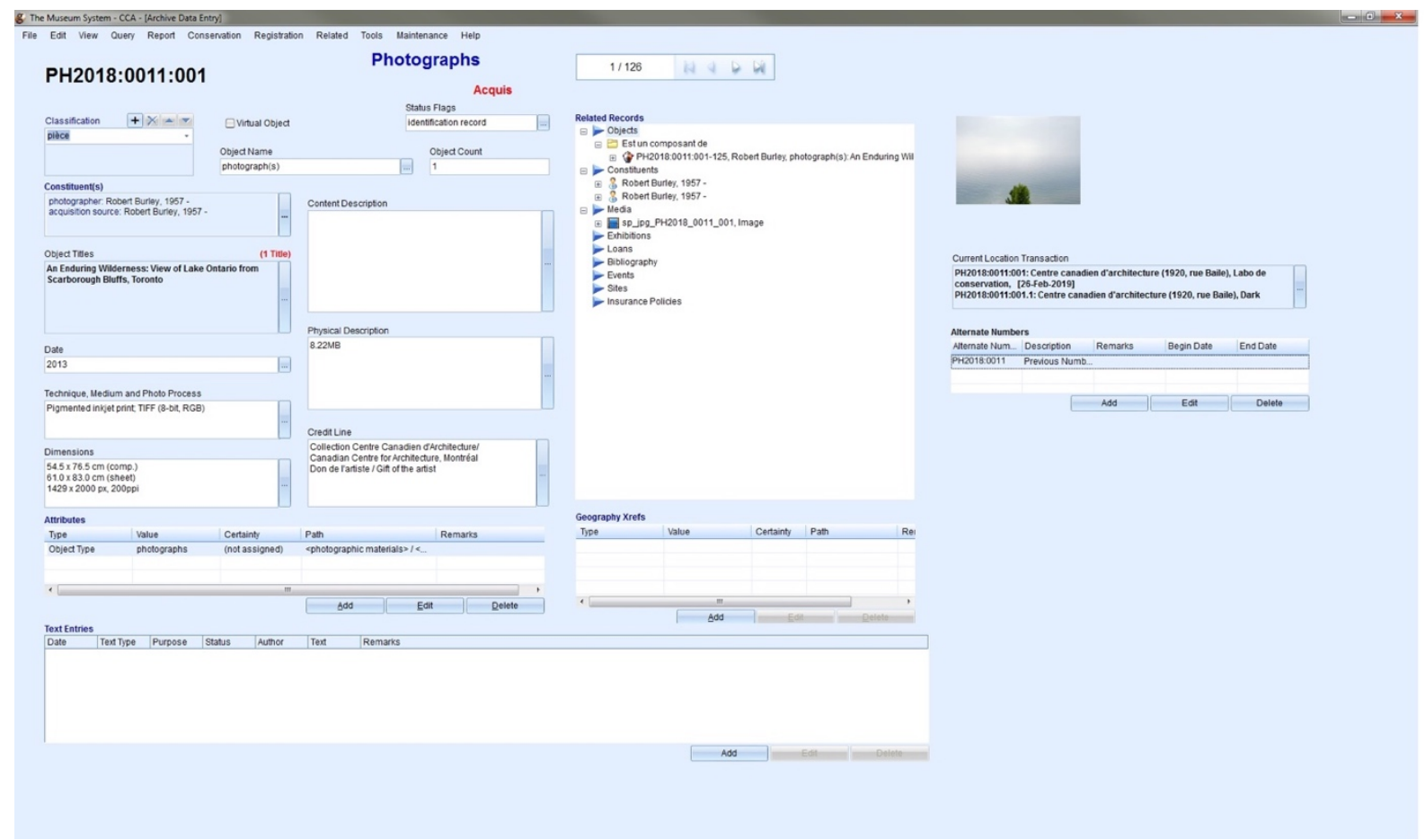




\section{Workflow'}

1. Donor offers born-digital photographs

2. Begin negotiations - send requirements for born digital photograph donation (Guideline for Donors: Transferring Digital Photographs to the CCA)

3. Receive and research born digital images on storage media or through other means

4. Prepare acquisition report and meeting with Acquisition Committee (accepted?)

5. Agreement created and signed by donor or vendor (identify it as a donation or purchase)

6. Registrar create accession record (record for management in TMS)

7. Transfer files to digital archivist and photography cataloguer

8. Assign collection to processing archivist

9. Run virus scan

10. Create dick image and extract files (if files are on storage media)

11. Brunnhilde inventory

12. Photography cataloguer renames files (using born-digital-photography-guidelines.pdf)

13. Flags any issues to digital archivist and aids in the development of cataloguing plan. (if necessary)

14. Create SIP using CCA tools

15. Populate description spreadsheet (using born-digital-photography-guidelines.pdf)

16. Send SIP to Archivematica

17. Enter Data in TMS

18. Notify digital archivist who will QA SIP and start Archivematica ingest

19. Archivematica preforms ingest

20. Photography cataloguer preform Archivematica QA

21. Send QA spreadsheet to archivist

22. Will the images be uploaded to Scope?

a. Yes? DIP is generated by Archivematica and automatically imported into scope

b. No? cataloguer will reformat and prepare images for TMS upload. (using borndigital-photography-guidelines.pdf)

23. Upload images onto TMS for web search

24. End.

\footnotetext{
${ }^{1}$ Refer to Appendix 1. for flowchart
} 


\section{Conclusion}

While this document aims to outline a precise and at times rigid set of rules for best practice, it should be remembered that these guidelines serve as recommendations and as a result the cataloguer, and institution by extension, should be flexible to review and revise this document as needed. Furthermore, as Jackie Dooley emphasizes in her $8^{\text {th }}$ Commandment for Special Collections Librarians in the Digital Age states "special collections staff often need not bear lead responsibility." (pg57) Here I want to highlight the importance of collaboration, both within the institution and with the larger community.

Some factors to consider:

- How to develop parent-child components for hybrid collections

- Automatic vs manual creation of fields. There have been attempts made to identify any field that holds autogenerated content. For the sake of efficiency and accuracy this should be monitored.

Since this material can so easily be altered and manipulated there needs to accountability and a diligence in recording the levels of intervention taking place. This notion, which is linked closely to the main objective of collections, is at the crux of the need for such a guideline. The goal being to ensure long-term preservation and access to born-digital photographs. As an example, a question that arises here is how to balance original and arranged order in documentation? And how to hold cataloguers and digital archivist accountable for their processing of this material.

Suggestion for future consideration:

- Creating fields in TMS dedicated to specifically born-digital photographs and generally to borndigital material 


\section{Definition of Terms}

Administrative Metadata: Information needed to help manage the digital object. Often included in administrative metadata is copyright and preservation information.

https://www.lib.umich.edu/preservation-and-conservation/digital-preservation-glossary

AIP: (Archival Information Package) This is what is stored within a digital repository. Included within an AIP is not only the digital object (s) but also any other information that helps to describe and understand the object(s). An AIP may have undergone transformation from ingest as a SIP in order to conform to the standards of the digital repository. This may include change of format or the addition of metadata. See also DIP and SIP. https://www.lib.umich.edu/preservation-and-conservation/digital-preservation-glossary

BIT: The fundamental unit of digital information storage, which can have a binary value of either 1 or 0 . https://wiki.harvard.edu/confluence/display/HoughtonTechnicalServices/Glossary+ relating + to + borndigital+materials

Born Digital: A digital object that has never had an analog form. They differ from documents, movies and photographs that may have been scanned or converted to a digital format. Born-digital information is distinguished from digitized, the latter describing a document created on paper that has been scanned http://files.archivists.org/pubs/free/SAA-Glossary-2005.pdf

Checksum: is a function used for validating data integrity. Also referred to as MD5 (Message-Digest algorithm 5). An algorithm or formula is applied against the source (typically a file and its content, such as the image of a scanned page from a book) in order to generate a unique, 128-bit hash value often called a checksum. In digital preservation processes, the MD5 checksum from when the content was created is compared to another checksum created after the content has been received or stored over a period of time. The values are compared and, if they match, this indicates that the data (e.g. The scanned page image) is intact and has not been altered. https://wiki.harvard.edu/confluence/display/HoughtonTechnicalServices/Glossary+ relating + to + borndigital+materials

Color Depth: The number of distinct colors that can be represented by a piece of hardware or software. Color depth is sometimes referred to as "bit" depth because it is directly related to the number of bits used for each pixel. https://www.bhphotovideo.com/explora/photography/tips-and-solutions/a-glossary-of-digital-photographyterms\#a

Compression: A method of reducing the size of a digital image file to free up the storage capacity of memory cards and hard drives. Compression technologies are distinguished from one another by whether or not they remove detail and color from the image. Joint Photographic Experts Group (JPEG) is a lossy compression format supported by JPEG, PDF and postscript language file formats. TIFF files are not and, as such, are far more stable than ipegs and other lossy file formats.

https://www.bhphotovideo.com/explora/photography/tips-and-solutions/a-glossary-of-digital-photographyterms\#a

Descriptive/Bibliographic Metadata: Metadata used for the discovery and interpretation of the digital object. Information used to search and locate an object such as title, author, subjects, keywords, and publisher. https://wiki.harvard.edu/confluence/display/HoughtonTechnicalServices/Glossary + relating + to + borndigital+materials

Derivatives: A copy of the artwork's file that has developed or been obtained from another file, often the master, usually created for exhibition of the artwork. A common practice is to

Produce an exhibition copy for display

HHps://www.macmillandictionary.com/dictionary/british/derivative_l?Q=derivatives 
Digital art: may be as simple as digital photography, or it may be much more complex in that it could be mixed media, dynamic, or could require recreation of an entire installation to render it effectively. More complex forms of digital art will likely require one-off solutions.

https://wiki.harvard.edu/confluence/display/HoughtonTechnicalServices/Glossary + relating + to + born-

digital+materials

Digital Negative: (DNG) is a publicly available raw image format owned by Adobe and used for digital photography. It's based on the TIFF/EP standard format and incorporates the use of metadata.

https://www.bhphotovideo.com/explora/photography/tips-and-solutions/a-glossary-of-digital-photography-

terms\#a

Digital object: A representation of some piece of information in digital form. This can include many types of information, including word processing files, images, and digital audio files.

https://www.lib.umich.edu/preservation-and-conservation/digital-preservation-glossary

Digital preservation: The maintenance and management of digital objects, including both those that are born digital and were converted to digital format from analog, so that they can be accessed and used by future users. https://www.lib.umich.edu/preservation-and-conservation/digital-preservation-glossary

Digital Provenance: Information on the origin of a digital object and also on any changes that may have occurred over the course of its life cycle.

https://www.lib.umich.edu/preservation-and-conservation/digital-preservation-glossary

Digital Repository: The organization or department responsible for the intake and maintenance of digital objects. https://www.lib.umich.edu/preservation-and-conservation/digital-preservation-glossary

Digital wrapper: A structured text file that binds digital object content files and their associated metadata together and that specifies the logical relationship of the content files. METS is an emerging, XML-based international standard for wrapping digital library materials.

https://wiki.harvard.edu/confluence/display/HoughtonTechnicalServices/Glossary+ relating + to + born-

digital+materials

DIP: (Dissemination Information Package) This is what is given to an end user for access purposes. Included within a DIP is not only the digital object(s) but also any other information that helps to describe and understand the object(s). The creation of a DIP from an AIP may involve some transformation of the object to make it suitable for end-users. https://www.lib.umich.edu/preservation-and-conservation/digital-preservation-glossary

EXIF: (Exchangeable Image File) Commonly used header format for storing metadata (e.g. Camera/lens/exposure information, time/date/, etc.) Within digital image files.

https://www.bhphotovideo.com/explora/photography/tips-and-solutions/a-glossary-of-digital-photographyterms \#a

Flash drive: a small device that plugs into computer's USB port and functions as a portable hard drive. https://wiki.harvard.edu/confluence/display/HoughtonTechnicalServices/Glossary + relating + to + born$\underline{\text { digital }+ \text { materials }}$

File Format: The way an image is saved to a digital camera's memory. JPEG, TIFF, and raw (DNG or other proprietary file formats) are the most common file formats found in digital cameras.

https://www.bhphotovideo.com/explora/photography/tips-and-solutions/a-glossary-of-digital-photographyterms \# a

Format/Technology Obsolescence: Occurs when a piece of software or hardware is no longer in wide use or available at all. This causes it to be difficult or impossible to use any files that depend on this software or hardware. https://www.lib.umich.edu/preservation-and-conservation/digital-preservation-glossary 
Ingest: One of the functions listed in the framework for OAIS. It involves taking an object (or objects) into a digital repository. https://www.lib.umich.edu/preservation-and-conservation/digital-preservation-glossary

JPEG: (Joint Photographic Experts Group) is the name of the group that developed the standard. JPG is a compression method for images.

https://wiki.harvard.edu/confluence/display/HoughtonTechnicalServices/Glossary+ relating + to + born-

digital+materials

Master: (copy) is also known as Preservation Master or Archival Master. An item from which duplicates are to be made. It is also A complete and accurate collection of data that is periodically updated and used for queries. (see native master)

Https://www2.archivists.org/glossary/terms/m/master

Megabyte: 1,024 Kilobytes, written MB, is used to refer to the size of files or media, such as hard drives. The number refers to the amount of information or image data in a file or how much information can be contained on a memory card, CD or DVD, hard drive or disk. https://www. bhphotovideo.com/explora/photography/tipsand-solutions/a-glossary-of-digital-photography-terms\#a

Metadata: Latin term meaning "information about information." In the digital realm, metadata is data that describes key information about the digital objects (image files, text files, digital audio/video) are different kinds of 'metadata' including bibliographic or descriptive metadata, technical metadata, administrative metadata and structural metadata. https://www.lib.umich.edu/preservation-and-conservation/digital-preservation-glossary

METS: Stands for Metadata Encoding and Transmission Standard. A framework for describing certain pieces of essential information (metadata) about a digital object. METS is the national standard for wrapping digital library materials, developed by the Digital Library Federation (DLF) and maintained by the Library of Congress. https://wiki.harvard.edu/confluence/display/HoughtonTechnicalServices/Glossary+relating + to + borndigital+materials https://www.lib.umich.edu/preservation-and-conservation/digital-preservation-glossary

Migration: One of the strategies used in digital preservation. Migration involves changing the format of a file, so it is able to be rendered with current hardware or software. This may cause changes in the 'look or feel' of a file. Migration includes refreshing as a means of digital preservation, however, it is not always possible to make an exact digital copy of a database or other information object and still maintain the compatibility of the object with a new generation of technology.

https://wiki.harvard.edu/confluence/display/HoughtonTechnicalServices/Glossary+ relating + to + borndigital+materials https://www.lib.umich.edu/preservation-and-conservation/digital-preservation-glossary

Native Master: The original version of the artwork received at time of acquisition.

Dunne, Naoise. "New Media Documentation at The Metropolitan Museum of Art, MRP," n.d., 138.

OAIS: (Open Archival Information System) It is an archival framework developed by the Consultative Committee for Space Data Systems (CCSDS). It is A conceptual framework for an archival system dedicated to preserving and maintaining access to digital information over the long term.

https://wiki.harvard.edu/confluence/display/HoughtonTechnicalServices/Glossary + relating + to + borndigital+materials

PDF: (Portable Document Format) is a file format, created by Adobe Systems, for document exchange in a manner independent of the application software, hardware, and operating system.

https://wiki.harvard.edu/confluence/display/HoughtonTechnicalServices/Glossary+ relating + to + borndigital+materials 
PREMIS: Stands for Preservation Metadata: Implementation Strategies. It is now in its third iteration. PREMIS metadata is contained within larger metadata schemas such as METS. PREMIS metadata structures and describes what sort of preservation has been done to a digital object. This might include taking the object into a new archive or changing the format of an object. https://www.lib.umich.edu/preservation-and-conservation/digitalpreservation-glossary

Preservation Description Information: (PDI) The information which is necessary for adequate preservation of the Content Information and which can be categorized as Provenance, Reference, Fixity, and Context information.

https://wiki.harvard.edu/confluence/display/HoughtonTechnicalServices/Glossary+relating + to + born-

digital+materials

Preservation copy: A copy of the artwork

Refreshment: Copying a digital object from one media format, such as a CD, to another, such as a hard drive.disk image DISK IMAGE: A computer file containing the complete contents and structure representing a data storage medium or device, such as a hard drive, floppy disk, optical disc, or USB flash drive. A disk image is usually made by creating a sector-by-sector copy of the source medium, thereby perfectly replicating the structure and contents of a storage device independent of the file system. https://www.lib.umich.edu/preservation-andconservation/digital-preservation-glossary

https://wiki.harvard.edu/confluence/display/HoughtonTechnicalServices/Glossary+ relating + to + borndigital+materials

Raw Files: Raw files, unlike ipegs, tiffs, and other file formats contain all of the data captured during the exposure in an unedited format. When processed, raw files can be adjusted far more extensively than images captured in other imaging formats, and can be saved as jpegs, tiffs, etc. The original raw file remains unaltered and can be reprocessed at any time for other purposes. https://www.bhphotovideo.com/explora/photography/tips-andsolutions/a-glossary-of-digital-photography-terms\#a

Resolution: Refers to the number of pixels, both horizontally and vertically, used to either capture or display an image. The higher the resolution, the finer the image detail will be.

https://www.bhphotovideo.com/explora/photography/tips-and-solutions/a-glossary-of-digital-photographyterms\#a

RGB Color (Red Green Blue): RGB is an additive color model in which red, green and blue light are added together in various ways to reproduce a broad array of colors for representation and display as images on computers and other digital devices. https://www.bhphotovideo.com/explora/photography/tips-and-solutions/aglossary-of-digital-photography-terms\#a

SIP (Submission Information Package): An external object representation prepared by the producer for the purpose of ingest into the Digital Preservation Repository, where it will be converted automatically to an Archival Information Package. See also AIP and DIP.

https://wiki.harvard.edu/confluence/display/HoughtonTechnicalServices/Glossary+ relating + to + borndigital+materials

Staging (data): is a storage area used for data processing during the extract, transform and load (ETL) process.

Structural Metadata: Information on how the digital object is organized. This may include the page or chapter order of a book, its table of contents or indexes. Structural metadata is often used by software programs. https://www.lib.umich.edu/preservation-and-conservation/digital-preservation-glossary

Technical Metadata: Information about aspects of the object often closely related either to its file format or the original software used to create the file. This may include things like the scanning equipment used to create a digital object and the settings used to create/modify it. 
https://www.lib.umich.edu/preservation-and-conservation/digital-preservation-glossary

TIFF: (Tagged Image File Format) is recognized as the best format for preservation and technical longevity. https://wiki.harvard.edu/confluence/display/HoughtonTechnicalServices/Glossary+ relating + to + born-

digital+materials

ZIP DRIVE: is a medium-to-high-capacity (at the time of its release) removable floppy disk storage system that was introduced by lomega in late 1994. Originally, Zip disks launched with capacities of $100 \mathrm{MB}$, but later versions increased this to first $250 \mathrm{MB}$ and then $750 \mathrm{MB}$.

https://wiki.harvard.edu/confluence/display/HoughtonTechnicalServices/Glossary+relating + to + born-

digital+materials 


\section{Bibliography}

Baldwin, Gordon, and Martin Jürgens. Looking at Photographs a Guide to Technical Terms. Getty, 2009.

Categories for the Description of Works of Art (CDWA) (Getty Research Institute).

www.getty.edu/research/publications/electronic_publications/cdwa/index.html. Accessed 10

June 2019.

CCO Toolkit - CCO Commons - Cataloging Cultural Objects, http://cco.vrafoundation.org/index.php/toolkit/. Accessed 10 June 2019.

Cofield, Melanie. LibGuides: Metadata Basics: Controlled Vocabularies. //guides.lib.utexas.edu/metadatabasics/controlled-vocabs. Accessed 10 June 2019.

DCMI: Dublin Core Metadata Element Set, Version 1.1: Reference Description. http://www.dublincore.org/specifications/dublin-core/dces/. Accessed 10 June 2019.

Descriptive Standards Roundtable. Best Guess Guidelines for Cataloguing Born Digital Material. 2016, http://www.archives.org.uk/images/Data_Standards/Best_Guess_Guidelines_v1.0 160325.pdf.

Digital Preservation Glossary | U-M Library. https://www.lib.umich.edu/preservation-andconservation/digital-preservation-glossary. Accessed 10 June 2019.

Dunne, Naoise. "New Media Documentation at The Metropolitan Museum of Art, MRP," n.d., 138.

Glossary - Digital Preservation Handbook. https://www.dpconline.org/handbook/glossary. Accessed 10 June 2019.

Glossary of DOCAM Cataloging Guide. http://www.docam.ca/en/glossary.html. Accessed 10 June 2019.

Introduction to Metadata (Getty Research Institute). http://www.getty.edu/research/publications/electronic_publications/intrometadata/. Accessed 10 June 2019.

Metadata Standards - CCO Commons - Cataloging Cultural Objects. http://cco.vrafoundation.org/index.php/toolkit/metadata_standards/. Accessed 10 June 2019.

Mugridge, Rebecca L. "Cataloging Cultural Objects: A Guide to Describing Cultural Works and Their Images." Library Collections, Acquisitions, \& Technical Services, vol. 31, no. 3-4, Sept. 2007. http://cco.vrafoundation.org/index.php/toolkit/cco_pdf version/

Pearce-Moses, Richard. A Glossary of Archival and Records Terminology. Society of American Archivists, 2005. http://files.archivists.org/pubs/free/SAA-Glossary-2005.pdf 
Poole, Nick, and Alex Dawson. "SPECTRUM Digital Asset Management." Canadian Heritage Information, 28 Aug. 2017, https://www.canada.ca/en/heritage-information-network/services/collectionsdocumentation-standards/spectrum-digital-asset-management.html.

PREMIS Editorial Committee. PREMIS Data Dictionary for Preservation Metadata, Version 3.0. 2015. http://www.loc.gov/standards/premis/v3/premis-3-0-final.pdf

Sustainability of Digital Formats: Planning for Library of Congress Collections. http://www.loc.gov/preservation/digital/formats/index.html. Accessed 10 June 2019.

University of California Born-Digital Content Common Knowledge. The UC Guidelines for Born-Digital Archival Description. 2017. https://github.com/uc-borndigital-ckg/uc-guidelines.

Weitz, Allan. "A Glossary of Digital Photography Terms." B\&H, 2017, https://www.bhphotovideo.com/explora/photography/tips-and-solutions/a-glossary-of-digitalphotography-terms.

Wisner, Melanie. Glossary Relating to Born-Digital Materials - Houghton Technical Services - Harvard Wiki. 2017, https://wiki.harvard.edu/confluence/display/HoughtonTechnicalServices/Glossary + relating + to +b orn-digital+materials. 


\section{Appendix 1a. Workflow Diagram Acquisition}

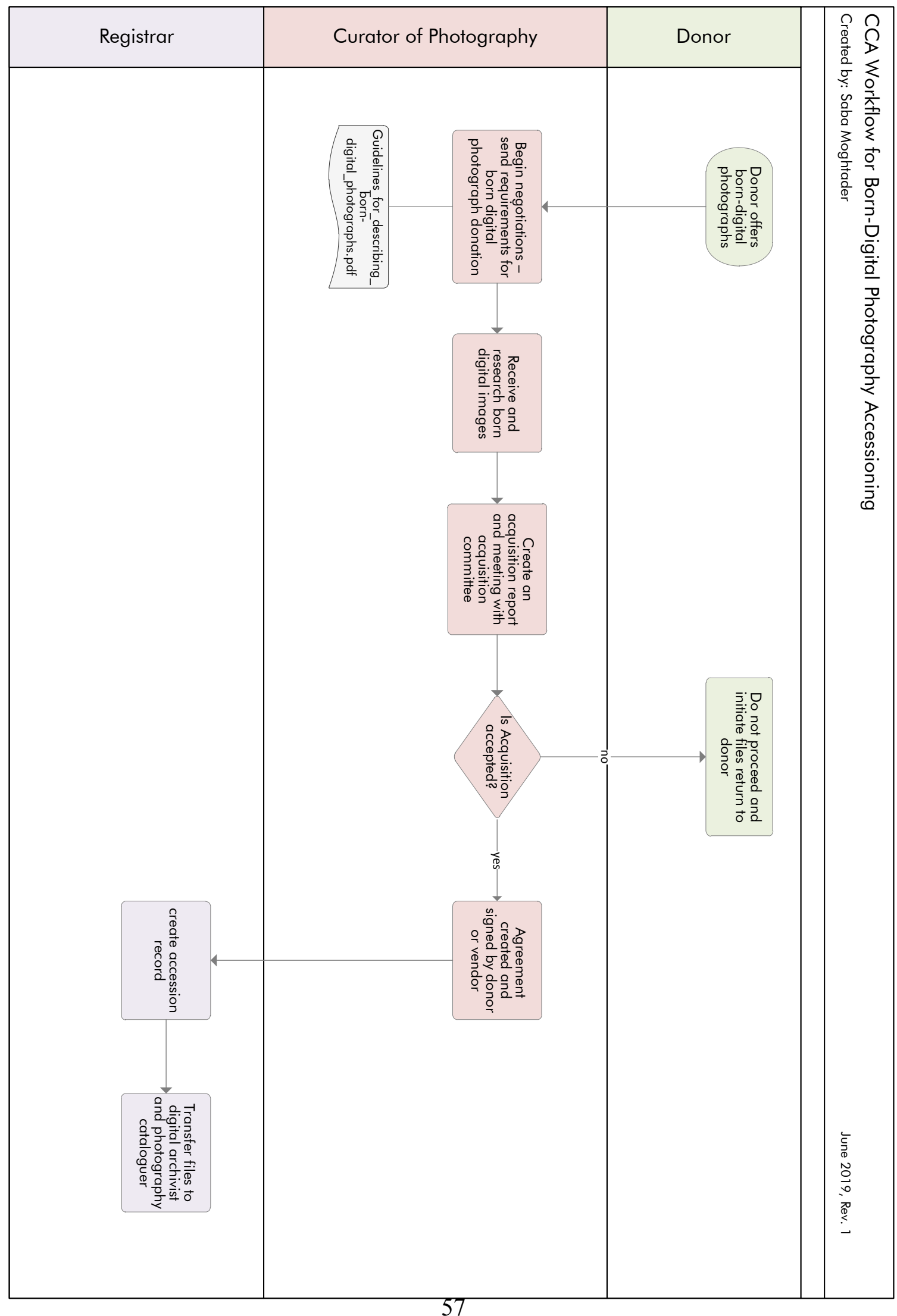




\section{Appendix 1b. Workflow Diagram Processing}

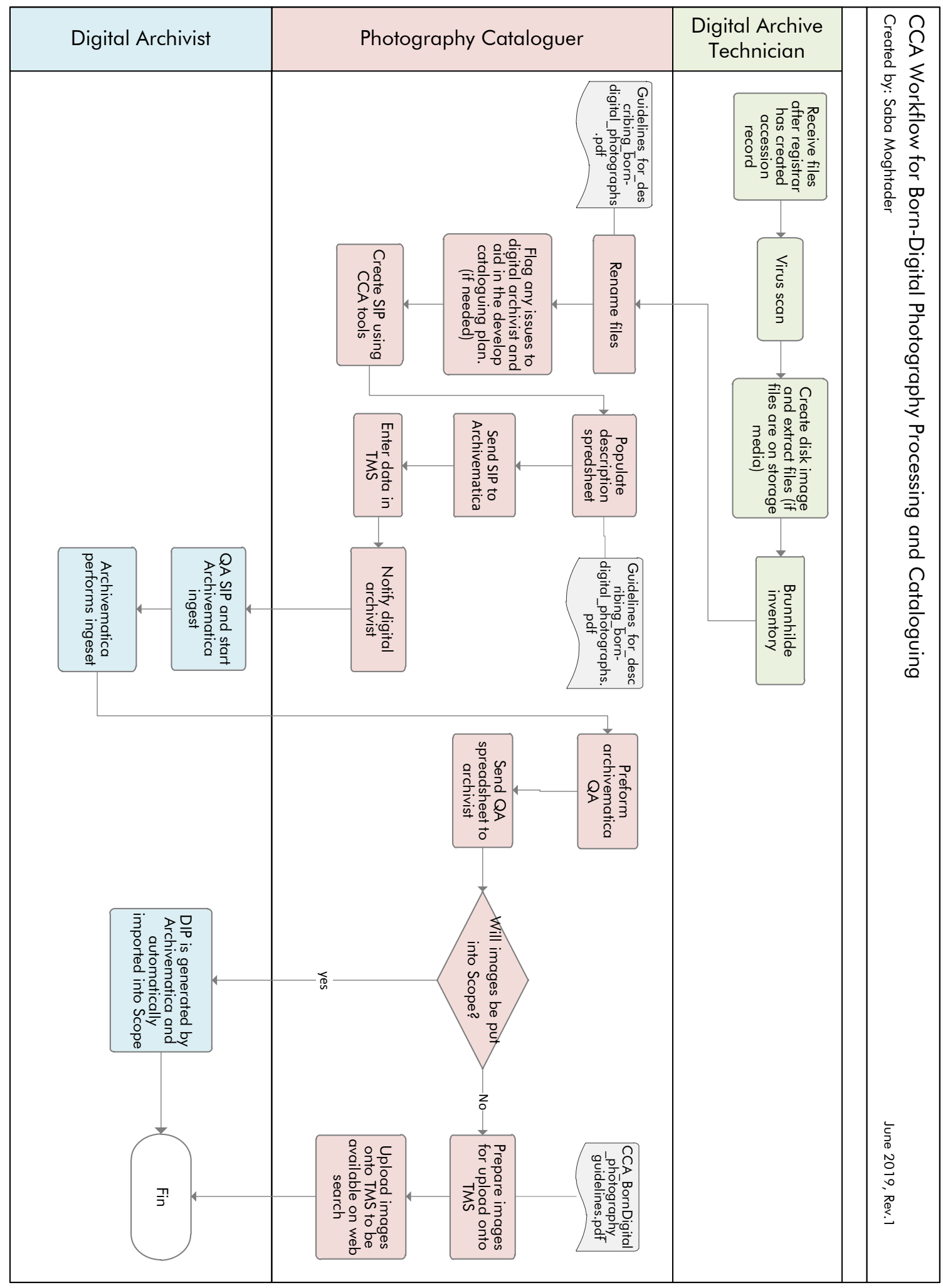




\section{Appendix 2. Chart to be used during cataloguing}

Recommendations for minimum requirements needed for $\mathrm{TMS}^{2}$ record and Archivematica $^{3}$ ingest

TMS: Mandatory

\begin{tabular}{|c|c|c|}
\hline Rubric & Example at group level & Example at item level \\
\hline Department & Photographs & Photographs \\
\hline Object Status & Acquis & Acquis \\
\hline $\begin{array}{l}\text { Method of } \\
\text { acquisition }\end{array}$ & Gift & Gift \\
\hline Classification & group & piece \\
\hline Object Count & 125 & 1 \\
\hline Object Flag & record for management need & Identification record \\
\hline Constituents & $\begin{array}{l}\text { Robert Burley, } 1957 \text { (role: Photographer) } \\
\text { Robert Burley, } 1957 \text { (role: acquisition } \\
\text { source) }\end{array}$ & $\begin{array}{l}\text { Robert Burley, } 1957 \text { (role: } \\
\text { Photographer) } \\
\text { Robert Burley, } 1957 \text { (role: } \\
\text { acquisition source) }\end{array}$ \\
\hline Credit line & $\begin{array}{l}\text { Collection Centre Canadien d'Architecture/ } \\
\text { Canadian Centre for Architecture, Montréal } \\
\text { Don de l'artiste / Gift of the artist }\end{array}$ & $\begin{array}{l}\text { Collection Centre Canadien } \\
\text { d'Architecture/ } \\
\text { Canadian Centre for Architecture, } \\
\text { Montréal } \\
\text { Don de l'artiste / Gift of the artist }\end{array}$ \\
\hline Copyright & (C) Robert Burley & (C)Robert Burley \\
\hline Object number & PH2018:001 1:001-125 & PH2018:0011:001 \\
\hline Object name & Photograph(s) & Photograph(s) \\
\hline $\begin{array}{l}\text { Attributes: } \\
\text { object type }\end{array}$ & & Photographs \\
\hline Date & $2012-2016$ & 2013 \\
\hline Title & An Enduring Wilderness & $\begin{array}{l}\text { An Enduring Wilderness: View of } \\
\text { Lake Ontario from Scarborough } \\
\text { Bluffs, Toronto }\end{array}$ \\
\hline $\begin{array}{l}\text { Technique, } \\
\text { Medium and } \\
\text { photo process }\end{array}$ & Pigmented Inkjet print, TIFF (8-bit, RGB) & TIFF (8-bit, RGB) \\
\hline Dimensions & & $1429 \times 2000$ px, 200ppi \\
\hline
\end{tabular}

\section{TMS: Optional}

\begin{tabular}{|l|l|l|}
\hline Rubric & Example at group level & Example at item level \\
\hline $\begin{array}{l}\text { Content } \\
\text { description }\end{array}$ & $\begin{array}{l}\text { A group of } 125 \text { digital images files } \\
\text { embedded with metadata and } 20 \text { printed } \\
\text { photographs from the group. The digital } \\
\text { files were sent via "WeTransfer". With }\end{array}$ & \\
\hline
\end{tabular}

\section{$1.1{ }^{2}$ adapted from Fiche Modèle + Rubriques á compléter from CCA-Division Numérique, numérisation \\ ${ }^{3}$ Adapted from existing CCA document titled: Metadata recommendations for born-digital photograph collections material (2018-11-20)}




\begin{tabular}{|l|l|l|}
\hline & $\begin{array}{l}\text { minimal intervention by the cataloguer the } \\
\text { images where organized and renamed to } \\
\text { reflect their associated object number and } \\
\text { ingested into Archivematica on February } \\
11,2019\end{array}$ & \\
\hline $\begin{array}{l}\text { Physical } \\
\text { description }\end{array}$ & $\begin{array}{l}20 \text { printed photographs, ?GB, 125 digital } \\
\text { files }\end{array}$ & 8.22MB \\
\hline
\end{tabular}

\section{Archivematica: Mandatory and Optional}

Group level record:

\begin{tabular}{|l|l|l|}
\hline Field name & Required? & Notes \\
\hline Title & Yes & Archivematica maps from this field \\
\hline Constituents & Yes & Name of the creator. Archivematica maps from this field \\
\hline Content description & Yes & $\begin{array}{l}\text { Description of the group files. Should at least include type } \\
\text { of format. Archivematica maps from this field }\end{array}$ \\
\hline Date & Yes & Archivematica maps from this field \\
\hline Object number & Yes & Archivematica maps from this field \\
\hline Physical description & $\begin{array}{l}\text { Recommended } \\
\text { (if applicable) }\end{array}$ & $\begin{array}{l}\text { Description of any technical information that might be } \\
\text { useful. ("created embedded additional metadata data in } \\
\text { the TIFF files. To access it open files in Adobe Bridge or } \\
\text { Photoshop"). Archivematica maps from this field }\end{array}$ \\
\hline Object type & Optional & Photographic material, born-digital \\
\hline
\end{tabular}

Item level record: no requirements for Archivematica.

For identical images that are both digital and prints, create a component for each image. In the component title, indicate that on is a digital image and the other is a print.

Note: if data in TMS is updated, the files need to be re-ingested in order to reflect changed. 


\section{Appendix 3.}

\section{Guideline for Donors: Transferring Digital Photographs to the CCA}

The CCA is committed to providing long-term preservation and access to born-digital photographs in its collection and in order to facilitate this, it is important that:

- all born-digital photographs are accompanied with appropriate information and documentation for understanding the context of their creation and use

- include Embedded Metadata which supports discovery, management and reuse - usually a composite of management, descriptive, technical, rights and preservation metadata. ${ }^{4}$

This guide is intended to support the acquisition committee and prospective donors to meet the goals stated above. It details the preferred methods of transferring digital photographs.

File Formats best practices

Tiff or Raw as master files

Jpeg for thumbnails and access files on some cases

\section{File naming best practices}

Title_year_creator

Example: of file structure and best naming practice

Folder: AnEnduringWilderness

Sub Folder: Shorelines

File: AnEnduringWildernessBluffer'sBeach_2013_RobertBurley

\section{Metadata}

There are a set of recommended metadata field to be included with the donation of born-digital photographs and are expected to be revised on a case by case basis. This information should be imbedded in the images donated.

$\begin{array}{cl}\text { Extif metadata } \\ \text { i. } & \text { File Name } \\ \text { ii. } & \text { Date Created } \\ \text { iii. } & \text { Dimensions } \\ \text { iv. } & \text { Resolution } \\ \text { v. } & \text { Bit Depth } \\ \text { vi. } & \text { Color Mode } \\ \text { vii. } & \text { Color Profile } \\ \text { viii. } & \text { Exposure Mode } \\ \text { ix. } & \text { Focal Length }\end{array}$

\footnotetext{
${ }^{4}$ definition taken from Spectrum Digital Asset Management - https://www.canada.ca/en/heritage-informationnetwork/services/collections-documentation-standards/spectrum-digital-asset-management.html
} 

x. ISO Speed
xi. Flash
xii. Shutter Speed Value
xiii. Aperture Value
xiv. Metering Mode
xv. Camera Model

\section{Digital Storage Media and transfer of files}

Acquisition of digital materials digital materials can arrive at the CCA in one of two forms.

1. Network transfer via WeTransfer, Dropbox or file transfer protocol (FTP)

2. Temporary transfer media that has been used solely for the purpose of transferring digital photographs to the CCA. Typically, USB thumb drive and external hard drives

Notes to the donor:

A selection of work must be sent to the CCA for Acquisition meeting Link to official acquisition process - https://www.cca.qc.ca/en/49498/cca-acquisition-procedure

If work not accepted the process of returning work will depend on the specific case. the digital files will be returned in the same manner that they were received. 


\section{Appendix B - Description Template}

This template visualized the description fields from the guidelines into an Excel worksheet to aid in the data collection by a cataloguer. It has been re-oriented for display in this paper. To make the process more efficient when using switch the rows and columns.

\begin{tabular}{|c|c|c|c|c|}
\hline & Definition & Example & Notes & $\begin{array}{l}\text { Alternative } \\
\text { Name }\end{array}$ \\
\hline Object number & $\begin{array}{l}\text { An unambiguous reference to } \\
\text { the resource within a given } \\
\text { context a unique alpha-numeric } \\
\text { identifier assigned to an object } \\
\text { or group of objects. }\end{array}$ & PH1998:0001:001-100 & $\begin{array}{l}\text { Mandatory for } \\
\text { TMS and } \\
\text { Archivematca } \\
\text { Populated at } \\
\text { group and item } \\
\text { level }\end{array}$ & $\begin{array}{l}\text { Component } \\
\text { number (created } \\
\text { at time of } \\
\text { acquisition) }\end{array}$ \\
\hline Object Count & $\begin{array}{l}\text { This field identifies the number } \\
\text { objects in a given record }\end{array}$ & 125 & $\begin{array}{l}\text { Populated at } \\
\text { group level }\end{array}$ & \\
\hline $\begin{array}{l}\text { Alternate } \\
\text { Name or } \\
\text { Number }\end{array}$ & $\begin{array}{l}\text { The name or number given to } \\
\text { file by creator or another } \\
\text { department }\end{array}$ & $\begin{array}{l}\text { BuffersParkBeach_Dec201 } \\
\text { 3_DSC3221 }\end{array}$ & & \\
\hline Classification & $\begin{array}{l}\text { Level of description most } \\
\text { common ones used in } \\
\text { photography are group, piece }\end{array}$ & Piece & $\begin{array}{l}\text { Mandatory for } \\
\text { TMS record. } \\
\text { Populated at } \\
\text { group and item } \\
\text { level }\end{array}$ & \\
\hline Title & $\begin{array}{l}\text { In the case of born-digital } \\
\text { photographs alternative titles } \\
\text { may be recorded as Alternative } \\
\text { title: property that refers to a } \\
\text { name or names of a resource } \\
\text { used as a substitute or } \\
\text { alternative to the formal title. } \\
\text { Note the distinction between } \\
\text { file title and a given title. In the } \\
\text { case of file titles this field can } \\
\text { be autogenerated at the time of } \\
\text { ingest making the process more } \\
\text { streamlined, however file titles } \\
\text { often do not capture the depth } \\
\text { of the object. }\end{array}$ & $\begin{array}{l}\text { File title: } \\
\text { BuffersParkBeach_Dec201 } \\
\text { 3_DSC3221. } \\
\text { Given title: An Enduring } \\
\text { Wilderness: Bluffer's Beach }\end{array}$ & $\begin{array}{l}\text { Mandatory for } \\
\text { both TMS record } \\
\text { and } \\
\text { Archivematica } \\
\text { ingest. } \\
\text { Populated at } \\
\text { group and item } \\
\text { level }\end{array}$ & Title \\
\hline
\end{tabular}




\begin{tabular}{|c|c|c|c|c|}
\hline Creator & $\begin{array}{l}\text { An entity primarily responsible } \\
\text { for making the content of the } \\
\text { resource. }\end{array}$ & Robert Burley & $\begin{array}{l}\text { Mandatory for } \\
\text { TMS record and } \\
\text { Archivematica } \\
\text { ingest } \\
\text { Populated at } \\
\text { group and item } \\
\text { level }\end{array}$ & Constituents \\
\hline Date(s) & $\begin{array}{l}\text { If the distinction between } \\
\text { different sorts of date is } \\
\text { necessary, the following sub } \\
\text { properties should be used. } \\
\text { Created, Issued, Available, } \\
\text { Modified, Valid, copyrighted, } \\
\text { submitted, accepted. }\end{array}$ & $\begin{array}{l}\text { Valid values: YYYY, } \\
\text { YYYY-MM, YYYY-MM- } \\
\text { DD }\end{array}$ & $\begin{array}{l}\text { Mandatory for } \\
\text { both TMS record } \\
\text { and } \\
\text { Archivematica } \\
\text { ingest } \\
\text { Populated at } \\
\text { group and item } \\
\text { level }\end{array}$ & Date \\
\hline Object Type & $\begin{array}{l}\text { Refers to a description of the } \\
\text { nature or genre of the content of } \\
\text { a resource (e.g. a stylistic } \\
\text { category, a function or an } \\
\text { aggregation level). To describe } \\
\text { the physical or digital } \\
\text { manifestation, use format. }\end{array}$ & $\begin{array}{l}\text { Photograph, album, born- } \\
\text { digital photograph }\end{array}$ & $\begin{array}{l}\text { Mandatory for } \\
\text { both TMS record } \\
\text { and optional for } \\
\text { Archivematica } \\
\text { ingest } \\
\text { Populated at item } \\
\text { level }\end{array}$ & \\
\hline Format & $\begin{array}{l}\text { The property format refers to } \\
\text { the file format }\end{array}$ & $\begin{array}{l}\text { Group level - hybrid } \\
\text { collection } \\
\text { Pigmented Inkjet print, } \\
\text { Tagged Image File Format } \\
\text { (8-bit, RGB) } \\
\text { Item level - born-digital } \\
\text { photography } \\
\text { Tagged Image File Format } \\
\text { (8-bit, RGB) }\end{array}$ & $\begin{array}{l}\text { Mandatory for } \\
\text { TMS record } \\
\text { Populated at } \\
\text { group and item } \\
\text { level }\end{array}$ & $\begin{array}{l}\text { Technique, } \\
\text { Medium and } \\
\text { photo process }\end{array}$ \\
\hline Dimensions & $\begin{array}{l}\text { Information about the } \\
\text { dimensions, size, or scale of the } \\
\text { work, presented in a syntax } \\
\text { suitable for display to the end- } \\
\text { user }\end{array}$ & $\begin{array}{l}1429 \text { x } 2000 \mathrm{px}, 200 \mathrm{ppi} \\
\text { (file size: } 8.22 \mathrm{MB} \text { ) }\end{array}$ & $\begin{array}{l}\text { Mandatory for } \\
\text { TMS record } \\
\text { Populated at item } \\
\text { level }\end{array}$ & Dimensions \\
\hline
\end{tabular}




\begin{tabular}{|c|c|c|c|c|}
\hline $\begin{array}{l}\text { Content } \\
\text { Description }\end{array}$ & $\begin{array}{l}\text { A textual description of the } \\
\text { work, including a discussion of } \\
\text { issues related to it. In the case } \\
\text { of born digital photographs it } \\
\text { will also refer to arrangement } \\
\text { interventions also. }\end{array}$ & $\begin{array}{l}\text { A group of } 125 \text { digital } \\
\text { images files embedded with } \\
\text { metadata and } 20 \text { printed } \\
\text { photographs from the } \\
\text { group. The digital files were } \\
\text { sent via "WeTransfer". } \\
\text { With minimal intervention } \\
\text { by the cataloguer the } \\
\text { images where organized } \\
\text { and renamed to reflect their } \\
\text { associated object number } \\
\text { and ingested into } \\
\text { Archivematica on February } \\
11,2019 \\
\text { An Enduring Wilderness: } \\
\text { Toronto's Natural Parklands } \\
\text { in a series commissioned in } \\
\text { 2012 by the City of Toronto } \\
\text { that chronicles the extensive } \\
\text { ravine network of sunken } \\
\text { rivers, forested vales, and } \\
\text { an extensive shoreline of } \\
\text { Toronto, which has been } \\
\text { historically overlooked, } \\
\text { neglected, or forgotten. } \\
\text { Robert Burley looks at these } \\
\text { sited as integral parts of } \\
\text { unban life, from lakeviews } \\
\text { of the Scarborough bluffs to } \\
\text { glimpses of the densely } \\
\text { wooded tails in the } \\
\text { Carolinian forests of Rouge } \\
\text { Park, questioning their role } \\
\text { in a diverse and growing } \\
\text { twenty-first century city. }\end{array}$ & $\begin{array}{l}\text { Recommended } \\
\text { for TMS and } \\
\text { Mandatory for } \\
\text { Archivematica } \\
\text { ingest } \\
\text { Populated at } \\
\text { group level }\end{array}$ & $\begin{array}{l}\text { Content } \\
\text { Description }\end{array}$ \\
\hline $\begin{array}{l}\text { Physical } \\
\text { Description }\end{array}$ & $\begin{array}{l}\text { A description of the appearance } \\
\text { of the work expressed in generic } \\
\text { terms, without reference to the } \\
\text { subject depicted. For born } \\
\text { digital photographs file size in } \\
\text { GB and total number of files }\end{array}$ & $1 \mathrm{~GB}, 125$ digital files & $\begin{array}{l}\text { Recommended } \\
\text { for TMS record } \\
\text { and mandatory for } \\
\text { Archivematica } \\
\text { ingest } \\
\text { Populated at } \\
\text { group and item } \\
\text { level }\end{array}$ & $\begin{array}{l}\text { Physical } \\
\text { Description }\end{array}$ \\
\hline
\end{tabular}




\begin{tabular}{|c|c|c|c|c|}
\hline Credit line & $\begin{array}{l}\text { A formal statement of the } \\
\text { copyright of a work, and/or any } \\
\text { restrictions placed on it. } \\
\text { A formal statement of the } \\
\text { copyright of a work, and/or any } \\
\text { restrictions placed upon it }\end{array}$ & (C)Robert Burley & $\begin{array}{l}\text { Mandatory for } \\
\text { TMS and } \\
\text { Archivematica } \\
\text { ingest }\end{array}$ & $\begin{array}{l}\text { Copyright } \\
\text { (Under rights \& } \\
\text { Reproductions) }\end{array}$ \\
\hline $\begin{array}{l}\text { Copyright } \\
\text { Line }\end{array}$ & $\begin{array}{l}\text { An identification of the } \\
\text { individual or group that holds } \\
\text { the rights to use, exhibit, or } \\
\text { reproduce a work along with an } \\
\text { indication of any existing } \\
\text { restrictions on its reproduction, } \\
\text { exhibition, or use. }\end{array}$ & $\begin{array}{l}\text { Collection Centre Canadien } \\
\text { d'Architecture/ } \\
\text { Canadian Centre for } \\
\text { Architecture, Montréal } \\
\text { Don de l'artiste/ Gift of the } \\
\text { artist }\end{array}$ & $\begin{array}{l}\text { Mandatory for } \\
\text { TMS and } \\
\text { Archivematica } \\
\text { ingest }\end{array}$ & Credit line \\
\hline Arrangement & $\begin{array}{l}\text { For born digital material which } \\
\text { has been 'arranged', e.g. into a } \\
\text { folder structure, a decision will } \\
\text { need to be taken as to the extent } \\
\text { to which this folder structure } \\
\text { should or should not be } \\
\text { replicated as levels of } \\
\text { arrangement/description. }\end{array}$ & $\begin{array}{l}\text { File path, } \\
\text { 1) No intervention by the } \\
\text { archivist } \\
\text { 2) Minimal intervention by } \\
\text { the archivist } \\
\text { 3) Intervention by the } \\
\text { archivist } \\
\text { 4) Post ingest intervention }\end{array}$ & $\begin{array}{l}\text { Recommended } \\
\text { for TMS record }\end{array}$ & $\begin{array}{l}\text { Content } \\
\text { Description }\end{array}$ \\
\hline $\begin{array}{l}\text { Source of } \\
\text { Acquisition }\end{array}$ & $\begin{array}{l}\text { General information about the } \\
\text { acquisition of born-digital } \\
\text { material, such as the source, } \\
\text { date, and type of acquisition, in } \\
\text { an Immediate Source of } \\
\text { Acquisition Note. }\end{array}$ & $\begin{array}{l}\text { The } 125 \text { digital files from } \\
\text { The Enduring Wilderness } \\
\text { series were donated to the } \\
\text { CCA by Robert Burley on } \\
\text { January } 21,2018 \text { as TIFF } \\
\text { Files though WeTransfer. } \\
\text { The images where } \\
\text { catalogued and ingested } \\
\text { into TMS on February } 11 \text {, } \\
2019 \text {. }\end{array}$ & $\begin{array}{l}\text { Recommended } \\
\text { for TMS record }\end{array}$ & $\begin{array}{l}\text { Refer to } \\
\text { guideline for } \\
\text { clear instruction } \\
\text { on where data } \\
\text { will be input }\end{array}$ \\
\hline Processor & $\begin{array}{l}\text { The name of the cataloguer or } \\
\text { processing archivist }\end{array}$ & $\begin{array}{l}\text { First name last name or } \\
\text { initials }\end{array}$ & $\begin{array}{l}\text { Mandatory for } \\
\text { this excel sheet }\end{array}$ & $\begin{array}{l}\text { Autogenerated } \\
\text { in TMS }\end{array}$ \\
\hline $\begin{array}{l}\text { Description } \\
\text { Status }\end{array}$ & Status of this document & $\begin{array}{l}\text { Valid value: Final, Revised, } \\
\text { Draft }\end{array}$ & $\begin{array}{l}\text { Mandatory for } \\
\text { this excel sheet }\end{array}$ & $\begin{array}{l}\mathrm{N} \text { need to input } \\
\text { into TMS }\end{array}$ \\
\hline METADATA & $\begin{array}{l}\text { Fill in the metadata based on } \\
\text { what is provided by the Donor. } \\
\text { This information can be found } \\
\text { in Adobe Bridge embedded in } \\
\text { the image files. }\end{array}$ & & $\begin{array}{l}\text { Highly } \\
\text { recommended but } \\
\text { not mandatory }\end{array}$ & \\
\hline
\end{tabular}




\begin{tabular}{|l|l|l|l|l|}
\hline File name & & & & \\
\hline Date Created & & & & \\
\hline Dimensions & & & & \\
\hline Resolution & & & & \\
\hline Bit Depth & & & & \\
\hline Color Mode & & & & \\
\hline Color Profile & & & & \\
\hline $\begin{array}{l}\text { Exposure } \\
\text { Mode }\end{array}$ & & & & \\
\hline Focal Length & & & & \\
\hline ISO Speed & & & & \\
\hline Flash & & & & \\
\hline $\begin{array}{l}\text { Shutter Speed } \\
\text { Value }\end{array}$ & & & & \\
\hline $\begin{array}{l}\text { Aperture } \\
\text { Value }\end{array}$ & & & & \\
\hline $\begin{array}{l}\text { Metering } \\
\text { Mode }\end{array}$ & & & & \\
\hline Camera Model & & & & \\
\hline
\end{tabular}




\section{Appendix C - Documentation Related to Interviews}

\section{List of Interviewees}

Photography

Louise Désy - Curator of Photography

Alan Reed - Digitization technician

Digital archivists

Stefana Breitwieser

Alexandra Jokinen

Photo Conservation

David Stevenson

$\underline{\text { Outside of CCA }}$

Tim Walsh

Bob Burley

Amy Furness (AGO)

Emily Sommers (UofT)

\section{List of Questions}

Curator of Photography

1. What is your role and what does it entail?

2. Do you have any experience with Born-Digital photographs?

3. How many born-digital images vs non-born-digital images do you currently have in the CCA collection?

4. Does the collections mandate include born digital material? Or does the mandate need to be modified to incorporate virtual objects?

5. Born-digital photographs take up a small section of the CCAs holdings how do you see the process being different from what is already being done?

The Digital Archivist

1. What is your role and what does it entail?

2. Do you have any experience with Born-Digital photographs?

3. What challenged have you faced in your time working with digital materials at the CCA? i. Could these challenges be reflected in the revision of existing workflows?

4. Do you know how many born-digital images vs other digital materials do you currently have in the CCA collections?

5. Can you tell me about how the Digital department came to be, and the challenge, steps and considerations taken in getting it up and running?

6. Can you show my or talk about the workflows that your work entails?

i. Do you follow any standards for description and metadata? 
ii. Where and is this information gathered and stored?

iii. How is it enforced?

7. whose responsibility is it to look after the digital files?

\section{Head of Collections}

1. What is your role and what does it entail?

2. Can you tell me a little about the collection here at the CCA?

3. Does the collections mandate include born digital material? Or does the mandate need to be modified to incorporate virtual objects?

Head of Media

1. What is your role and what does it entail?

2. Do you have any experience with born-digital material? if so what challenged have you faced in your time working with digital materials?

3. Can you tell me about how the Digital department came to be, and the challenge, steps and considerations taken in getting it up and running?

\section{Donors}

1. Can you tell me a little about your work and your process?

2. What has made decide to donate born-digital photographs?

3. What consideration have you made in deciding what kind of metadata to include thus far?

4. Do you think it's important to have prints to accompany the digital files?

i. What do you consider to be the original?

Professionals Outside the CCA (who work with born-digital materials)

1. What is your role and what does it entail?

2. Does your institution collect and preserve with born-digital materials?

3. What are some of the challenges you've faced in dealing with this material?

4. Can you speak to some of the workflows you use in processing and cataloguing this material?

i. What was taken into consideration in developing this workflow?

ii. How are these workflows implemented?

8. Can you speak about the kinds of metadata kinds that you use?

iv. Do you follow any standards for description and metadata?

v. Where and is this information gathered and stored?

vi. How is it enforced?

9. whose responsibility is it to look after the digital files? 


\section{Recruitment Email and Consent Form}

Hello

My name is Saba Moghtader. I am a graduate student at Ryerson University in the faculty of Communication and Design. I am contacting you to see if you might be interested in participating in a research study. This research is being done as part of my master's project and my supervisor's name is Dee Psaila, faculty member in the Film and Photography Preservation and Collections Management Program. This research project aims to investigate how institutions are adapting to collecting and housing physical objects vs. digital ones. You have been selected to participate because of your experience in working with digital-born archives. Your participation is voluntary, and you have to option to remain anonymous. Your participation will involve a 30 min in-person or over the phone conversation about how you and your institution have adapted to collecting and preserving born-digital objects, with a focus on photography. The goal is to conduct said interviews throughout the month of March and April 2019.

If you are interested in more information about the study or would like to volunteer, please reply to this email or call me at 6474050914.

Thank you kindly for you time, Saba Moghtader 
Interview Consent Form

INFORMED CONSENT TO PARTICIPATE IN A RESEARCH PROJECT:

“Adapting to Born-Digital Photographs: A Case Study at the Canadian Centre for Architecture”

INTRODUCTION

You are being invited to participate in a research study. Please read this consent form so that you understand what your participation will involve. Before you consent to participate, please ask any questions to be sure you understand what your participation will involve. If you are interested in participating, please read on.

\section{PURPOSE OF THE STUDY}

I am a graduate student at Ryerson University working with Dee Psaila, faculty member in the Film and Photography preservation and collections management program in the faculty of Communication and Design. This research will contribute to the completion of a Master's Research Project that will fulfill the requirements of my master's degree.

This form asks for your agreement to participate in a research project on preservation techniques as they pertain to born-digital photographs. Your participation involves answering questions providing insight on some of your opinions and practices in regard to overcoming and adapting to the preservation born digital collections materials. You have been selected along with a number of other professionals based on your experience working with digital materials. Your participation is expected to take approximately 30-40 minutes. The potential risks from this project are considered minimal: by taking part in this study, you will be asked to share your experiences and your expertise on some issues in the subject matter. The research will use your responses, together with other textual material gathered, and draw conclusions about the current state of born digital and photographic preservation. By taking part in this study you are helping to expand knowledge on the subject, that will provide greater understanding of the practices and procedures of digital-born preservation in Cultural Heritage Institutions. Additionally, others, including collections managers, archivists, photographers, may benefit from your participation today by gaining increased knowledge as they strive to adapt to their growing born digital photography collections.

\section{YOUR PARTICIPATION}

- If you agree to participate, you will be asked to answer a number of questions about the kind of work you do and the experiences and challenges you've faced thus far.

- The interview will be organized in a semi-structured style.

- Your participation will take approximately 30-40 minutes.

- The interview will be conducted in your office or common space in the institution. Arrangements to meet elsewhere can be made

- Beyond your time, there are no additional costs associated with participation in this research.

\section{POTENTIAL BENEFITS}

- Increase and expand general knowledge to understanding of the practices and procedures of digital-born preservation 
- As a member of the digital community, the resulting guidelines on born-digital photographic can be adapted to your growing collection.

\section{CONFIDENTIALITY, PROTECTIONS AND POTENTIAL RISKS}

- The possible risks or discomforts associated with participation in this research are minimal. Due to the nature of the questions asked, you may be asked to share information that may be sensitive and confidential to your department or institution. To remedy this, please be aware that:

$\circ$ you may refuse to answer any questions or line of questioning that you do not feel comfortable with during the interview or at any point after.

- Your confidentiality will be protected by keeping the data anonymous, if you request to remain anonymous. There is check box in the signature section of this agreement, if you wish to remain anonymous please check the box.

- Lastly, the interview will be recorded, and a transcript will be published in the final research paper. Please contact the researcher if you would like to review or have a copy of the recording or transcript. If you wish to not have your responses recorded please make note in the signature section of this agreement. Recordings will be stored with the researcher and destroyed once transcripts have been made (by the primary researcher) for the purpose of publication.

\section{INCENTIVES AND COSTS FOR PARTICIPATION}

- There will be no monetary incentives to participate in this study.

- If we agree to meet outside the institution and transportation is required, reimbursement may be provided. These arrangements will be made prior to the interview.

\section{VOLUNTARY PARTICIPATION AND WITHDRAWAL}

- Please be aware that your participation is voluntary and that you are not required to participate in this research, refusal to participate will not involve any penalty or loss of benefits to which you are otherwise entitled, and you may discontinue your participation at any time. However, if you decide to withdraw your participation, you must alert the researcher no later than May 31, 2019. You may also omit responses to any questions you choose not to answer.

\section{RESOURCES AND CONTACT INFORMATION}

- If you should experience any negative outcomes from this research, please be aware that you may contact the researcher Saba Moghtader at (647) 405 0914, for assistance.

- This research is being conducted by Saba Moghtader, a graduate student, and Dee Psaila, a faculty member in the Film and Photography Preservation and Collections Management at Ryerson University, Toronto. If you have questions regarding this study or would like to be informed of the results when the study is completed, please contact the researcher(s) at smoghtader@ryerson.ca or denise.psaila@ontario.ca.

\section{AGREEMENT TO PARTICIPATE}

Your signature below indicates that you have read the information in this agreement and have had a chance to ask any questions you have about the study. Your signature also indicates that you 
agree to participate in the study and have been told that you can change your mind and withdraw your consent to participate at any time. You have been given a copy of this agreement.

You have been told that by signing this consent agreement you are not giving up any of your legal rights.

Name of Participant (please print)

$\overline{\text { Signature of Participant }} \quad \overline{\text { Date }}$

I wish to remain anonymous and not have my name or position published anywhere in the final research paper.

I agree to be audio-recorded for the purposes of this study. I understand how these recordings will be stored and destroyed.

Signature of Participant

Date

Signature of Researcher

Date 


\section{Works Cited}

“About.” Accessed August 8, 2019. https://www.cca.qc.ca/en/about.

Bak, Greg. 2016. "Not meta just data: Redefining content and metadata in archival theory and practice.” Journal of Archival Organization 13 (1-2): 2-18.

Berdini, Annalise, Charles Macquarie, Shira Peltzman and Kate Tasker. "Describing Digital: The Design and Creation of a Born-Digital Archival Description Standard at the University of California Libraries.” Journal of Western Archives 9, no. 1 (2018): 1-24.

Calanag, Maria Luisa, Koichi Tabata, and Shigeo Sugimoto. 2002. “Linking collection management policy to metadata for preservation - a guidance model to define metadata description levels in digital archives." proceedings of the international conference on Dublin core and metadata for e-communities, 2002: October 13-17, 2002, Florence, Italy. In Firenze University Press.

Dappert, Angela and Marcus Enders. "Digital Preservation Metadata Standards.” Information standards Quarterly, no.22 (2010): Pg4-13.

Erway, Ricky. "Defining 'Born Digital.”' OCLC Online Computer Library Center, Inc, 2010, 14.

Keough, Brian and Mark Wolfe. "Moving the Archivist Closer to the Creator: Implementing Integrated Archival Policies for Born Digital Photography at Colleges and Universities." Journal of Archival Organization 10, no. 1 (2012): 69-83.

PREMIS Editorial Committee. "PREMIS Data Dictionary for Preservation Metadata, Version $3.0, " 2015$, pg.3.

Redwine, Gabriela, Megan Barnard, Kate Donovan, Erika Farr, Michael Forstrom, William M Hansen, Jeremy Leighton John, Nancy Kuhl, Seth Shaw, and Susan Thomas. Born Digital: 
Guidance for Donors, Dealers, and Archival Repositories. Council on Library and Information Resources, 2013.

Rubinstein, Daniel, and Katrina Sluis. 2013. Notes on the margins of metadata: Concerning the undecidability of the digital image. Photographies 6 (1): 151.

Scott, Marian. "Montreal: Architecture Icon Phyllis Lambert Helped Shape a City." Montreal Gazette. January 21, 2017. https://montrealgazette.com/news/local-news/phyllis-lambertlooks-back-on-90-years-in-art-and-architecture.

Stephen Heyman.. "Photos, Photos Everywhere.” The New York Times, July 29, 2015, accessed July 14，2016,vhttp://www.nytimes.com/2015/07/23/arts/international/photos-photoseverywhere.html.

Severson, Sarah. "Archiving Digital Photographs." In the Complete Guide to Personal Digital Archiving, ed. By Brianna H. Marshall. ALA Editions, 2017. Pg. 2

“The DOCAM Research Alliance.” DOCAM. Accessed May 8, 2019. http://www.docam.ca/.

Thibodeau, Kenneth. 2018. "Overview of Technological Approaches to Digital Preservation and Challenges in Coming Years." Washington, D.C.: Council on Library and Information Resources. Accessed Nov 4, 2018, https://www.clir.org/pubs/reports/pub107/thibodeau/ Ybarra, Amelia Boogen. "Born-Digital Art: Documentation Models as a Conservation Measure." Ge-Conservation 1, no. 11 (2016): 165-71. 


\section{Bibliography}

Bak, Greg. 2016. Not meta just data: Redefining content and metadata in archival theory and practice. Journal of Archival Organization 13 (1-2): 2-18.

Baldwin, Gordon, and Martin Jürgens. Looking at Photographs a Guide to Technical Terms. Getty, 2009.

Berdini, Annalise. "Describing Digital: The Design and Creation of a Born-Digital Archival Description Standard at the University of California Libraries." Journal of Western Archives 9, no. 1 (2018): 1-24.

Calanag, Maria Luisa, Koichi Tabata, and Shigeo Sugimoto. 2002. "Linking Collection Management Policy to Metadata for Preservation - a Guidance Model to Define Metadata Description Levels in Digital Archives," Proceedings of the international conference on Dublin core and metadata for e-communities, 2002: October 13-17, 2002, Florence, Italy. In Firenze University Press.

Categories for the Description of Works of Art (CDWA) (Getty Research Institute).

www.getty.edu/research/publications/electronic_publications/cdwa/index.html. Accessed 10 June 2019.

CCO Toolkit - CCO Commons - Cataloging Cultural Objects, http://cco.vrafoundation.org/index.php/toolkit/. Accessed 10 June 2019.

Cocciolo, Anthony. "Challenges to Born-Digital Institutional Archiving: The Case of a New York Art Museum.” Edited by Dr Anne Thurston. Records Management Journal 24, no. 3 (November 11, 2014): 238-50. https://doi.org/10.1108/RMJ-04-2014-0023.

Cofield, Melanie. LibGuides: Metadata Basics: Controlled Vocabularies.

//guides.lib.utexas.edu/metadata-basics/controlled-vocabs. Accessed 10 June 2019. 
Dappert, Angela and Marcus Enders. "Digital Preservation Metadata Standards." Information Standards Quarterly, no.22 (2010): Pg4-13.

DCMI: Dublin Core Metadata Element Set, Version 1.1: Reference Description. http://www.dublincore.org/specifications/dublin-core/dces/. Accessed 10 June 2019.

Descriptive Standards Roundtable. Best Guess Guidelines for Cataloguing Born Digital Material. 2016 , http://www.archives.org.uk/images/Data_Standards/Best_Guess_Guidelines_v1.0_16032 5.pdf.

Di Bello, Patrizia, Colette E. Wilson, and Shamoon Zamir, eds. The Photobook: From Talbot to Ruscha and Beyond. London; New York: I.B. Tauris, 2012.

"Digital Art History: A Subject in Transition. Computers and the History of Art Series, Volume 1." Accessed December 2, 2018. $\underline{\text { https://web-a-ebscohost- }}$ com.ezproxy.lib.ryerson.ca/ehost/ebookviewer/ebook/bmxlYmtfXzEwODMzN19fQU41 ?sid=356bcb45-311b-47a8-9640254a818df803@sessionmgr4010\&vid=0\&format=EB\&rid=1.

Digital Preservation Glossary | U-M Library. https://www.lib.umich.edu/preservation-andconservation/digital-preservation-glossary. Accessed 10 June 2019.

Dooley, Jackie. "Ten Commandments for Special Collections Librarians in the Digital Age." RBM: A Journal of Rare Books, Manuscripts, and Cultural Heritage 10, no. 1 (March 1, 2009): 51-60. https://doi.org/10.5860/rbm.10.1.317.

Dooley, Jackie. "Viewpoint: How 'special' are Born-Digital Collections?" Art Libraries Journal35, no. 3 (2010): 3-4. 
Dunne, Naoise. "New Media Documentation at The Metropolitan Museum of Art, MRP," n.d., 138.

Dylan Cave. “'Born Digital'—Raised an Orphan?: Acquiring Digital Media through an Analog Paradigm.” The Moving Image 8, no. 1 (2008): 1-13. https://doi.org/10.1353/mov.0.0002.

Erway, Ricky, Ben Goldman, Matthew McKinley, and OCLC Research. Agreement Elements for Outsourcing Transfer of Born Digital Content. Dublin, Ohio: OCLC Research, 2014. http://www.oclc.org/content/dam/research/publications/library/2014/oclcresearch-borndigital-content-transfer-2014.pdf.

Erway, Ricky. "Defining 'Born Digital.”' OCLC Online Computer Library Center, Inc, 2010, 14.

Erway, Ricky, and OCLC Research. You've Got to Walk before You Can Run: First Steps for Managing Born-Digital Content Received on Physical Media. Dublin, Ohio: OCLC Research, 2012. http://www.oclc.org/content/dam/research/publications/library/2012/2012-06.pdf.

Gerard, Alexis. "Digital Photography: A Medium Is (Re)Born.” Computer Pictures 11, no. 2 (1993): 2.

Glossary - Digital Preservation Handbook. https://www.dpconline.org/handbook/glossary. Accessed 10 June 2019.

Glossary of DOCAM Cataloging Guide. http://www.docam.ca/en/glossary.html. Accessed 10 June 2019.

Grundberg, Andy. "Photography View; Two Camps Battle Over the Nature of the Medium." The New York Times, August 14, 1983, sec. Arts. 
https://www.nytimes.com/1983/08/14/arts/photography-view-two-camps-battle-over-thenature-of-the-medium.html.

"Home - Digital Preservation Handbook." Accessed December 1, 2018.

https://dpconline.org/handbook.

Introduction to Metadata (Getty Research Institute).

http://www.getty.edu/research/publications/electronic publications/intrometadata/. Accessed 10 June 2019.

Joslin, Blanche. "A CUSTOM DIGITAL FORENSICS WORKFLOW AND DIGITAL PRESERVATION LAB FOR THE ARCHIVES OF ONTARIO," n.d., 55.

Jürgens, Martin. "The History and Conservation of Digital Prints." Accessed March 7, 2019. http://www.getty.edu/conservation/publications_resources/newsletters/22_3/feature.html.

Kaczmarek, Joanne. "The Complexities of Digital Resources: Collection Boundaries and Management Responsibilities." Journal of Archival Organization 4, no. 1-2 (April 11, 2007): 215-27. https://doi.org/10.1300/J201v04n01_11.

Keough, Brian and Mark Wolfe. "Moving the Archivist Closer to the Creator: Implementing

Integrated Archival Policies for Born Digital Photography at Colleges and Universities." Journal of Archival Organization 10, no. 1 (2012): 69-83.

Kronenberg, Alex. "How Metadata Transforms Image Management for the Art Gallery of New South Wales." Accessed February 1, 2019. https://www.fotoware.com/blog/howmetadata-transforms-image-management-for-the-art-gallery-of-new-south-wales.

Metadata Standards - CCO Commons - Cataloging Cultural Objects.

http://cco.vrafoundation.org/index.php/toolkit/metadata_standards/. Accessed 10 June 2019. 
Mugridge, Rebecca L. “Cataloging Cultural Objects: A Guide to Describing Cultural Works and Their Images." Library Collections, Acquisitions, \& Technical Services, vol. 31, no. 3-4, Sept. 2007. http://cco.vrafoundation.org/index.php/toolkit/cco pdf version/

Pearce-Moses, Richard. A Glossary of Archival and Records Terminology. Society of American Archivists, 2005. http://files.archivists.org/pubs/free/SAA-Glossary-2005.pdf

Poole, Nick, and Alex Dawson. "SPECTRUM Digital Asset Management." Canadian Heritage Information, 28 Aug. 2017, https://www.canada.ca/en/heritage-informationnetwork/services/collections-documentation-standards/spectrum-digital-assetmanagement.html.

PREMIS Editorial Committee. PREMIS Data Dictionary for Preservation Metadata, Version 3.0. 2015. http://www.loc.gov/standards/premis/v3/premis-3-0-final.pdf.

Rafferty, Emily, and Becca Pad. "Better Together: A Holistic Approach to Creating a Digital Preservation Policy in an Art Museum." Art Documentation: Journal of the Art Libraries Society of North America 36, no. 1 (March 2017): 149-62. https://doi.org/10.1086/691378.

Redwine, Gabriela, Megan Barnard, Kate Donovan, Erika Farr, Michael Forstrom, William M Hansen, Jeremy Leighton John, Nancy Kuhl, Seth Shaw, and Susan Thomas. Born Digital: Guidance for Donors, Dealers, and Archival Repositories. Council on Library and Information Resources, 2013.

Rubinstein, Daniel, and Katrina Sluis. 2013. NOTES ON THE MARGINS OF METADATA: Concerning the undecidability of the digital image. Photographies 6 (1): 151. https://doi.org/10.1080/17540763.2013.788848. 
Scott, Marian. "Montreal: Architecture Icon Phyllis Lambert Helped Shape a City." Montreal Gazette. January 21, 2017. https://montrealgazette.com/news/local-news/phyllis-lambertlooks-back-on-90-years-in-art-and-architecture.

Severson, Sarah. “Archiving Digital Photographs.” In the Complete Guide to Personal Digital Archiving, ed. By Brianna H. Marshall. ALA Editions, 2017.

Stephen Heyman.. "Photos, Photos Everywhere.” The New York Times, July 29, 2015, accessed July 14, 2016, http://www.nytimes.com/2015/07/23/arts/international/photos-photoseverywhere.html.

“Sustainability of Digital Formats: Planning for Library of Congress Collections." Webpage. Accessed June 21, 2019. http://www.loc.gov/preservation/digital/formats/index.html.

“The DOCAM Research Alliance.” DOCAM. Accessed May 8, 2019. http://www.docam.ca/. Thibodeau, Kenneth. 2018. "Overview of Technological Approaches to Digital Preservation and Challenges in Coming Years." Washington, D.C.: Council on Library and Information Resources. Accessed Nov 4, 2018, https://www.clir.org/pubs/reports/pub107/thibodeau/ University of California Born-Digital Content Common Knowledge. The UC Guidelines for BornDigital Archival Description. 2017. https://github.com/uc-borndigital-ckg/uc-guidelines. Walsh, David, Mark M. Hall, Paul Clough, and Jonathan Foster. "Characterising Online Museum Users: A Study of the National Museums Liverpool Museum Website.” International Journal on Digital Libraries, July 5, 2018. https://doi.org/10.1007/s00799-018-0248-8.

Weitz, Allan. “A Glossary of Digital Photography Terms.” $B \& H, 2017$, https://www.bhphotovideo.com/explora/photography/tips-and-solutions/a-glossary-ofdigital-photography-terms. 
Wisner, Melanie. Glossary Relating to Born-Digital Materials - Houghton Technical Services Harvard Wiki. 2017, https://wiki.harvard.edu/confluence/display/HoughtonTechnicalServices/Glossary+relatin g+to+born-digital+materials.

Ybarra, Amelia Boogen. "Born-Digital Art: Documentation Models as a Conservation Measure." Ge-Conservation 1, no. 11 (2016): 165-71. 